Check for updates

Cite this: RSC Adv., 2017, 7, 40074

Received 7th June 2017

Accepted 30th July 2017

DOI: $10.1039 / \mathrm{c} 7 \mathrm{ra06389j}$

rsc.li/rsc-advances

\section{Targeted delivery of bromelain using dual mode nanoparticles: synthesis, physicochemical characterization, in vitro and in vivo evaluation $\uparrow$}

\author{
Rozita Nasiri, ${ }^{a}$ Javad Hamzehalipour Almaki, ${ }^{a}$ Ani Idris, (D) *a Mahtab Nasiri, ${ }^{\text {b }}$ \\ Muhammad Irfan, ${ }^{a}$ Fadzilah Adibah Abdul Majid, ${ }^{c}$ Hamid Rashidi Nodeh ${ }^{d}$ \\ and Rosnani Hasham ${ }^{\mathrm{e}}$
}

\begin{abstract}
The engineering, characterization, and application of dual-functional delivery vehicle "SPIONs-Br-FA" are reported. In this study, a citrate-coated SPIONs (superparamagnetic iron oxide nanoparticles) drug-delivery vehicle was conjugated with $\mathrm{Br}$ (bromelain), a phytotherapeutic anticancer agent, and finally immobilized with FA (folic acid), as a targeting moiety to the FAR+, folate receptor positive, cancer cells. Then, in vitro compatibility tests were performed to confirm the biocompatibility of the engineered system. A cytotoxicity study was carried out, which showed a significant dose advantage with SPIONs-Br-FA in reducing the $\mathrm{IC}_{50}$ values of $\mathrm{FAR}+$ cancer cells compared with neat $\mathrm{Br}$. Through morphological alternation studies, it was disclosed that the SPIONs-Br-FA-treated cells had undergone apoptosis, since shrinkage as well as apoptotic bodies were obviously observed. We demonstrated that SPIONs$\mathrm{Br}$-FA was a good candidate to suppress the migration of the FAR+ cancer cells as well as to inhibit colony formation of the FAR+ cancer cells compared to SPIONs-Br. We found that the apoptosis percentage was sharply increased in the FAR+ cancer cells treated by SPIONs-Br-FA compared to those treated by neat $\mathrm{Br}$. Moreover, the qualitative and quantitative biodistribution study performed on the vital organs and tumor indicated a significant tumor targetability of the SPIONs-FA. Next, we demonstrated the administration of SPIONs-Br-FA through the tail vein could reduce the tumor burden in 4T1-bearing mice and also increased their lifespan when compared with SPIONs-Br and neat $\mathrm{Br}$ at the same concentration of bromelain. In conclusion, the results indicated that the synthesized SPIONs-Br-FA is a promising tool in the field of biomedicine, particularly in cancer therapy.
\end{abstract}

\section{Introduction}

Cancer remains a major health problem and involves various genetic and cellular abnormalities. ${ }^{1,2}$ In the past decade, it has received much attention from researchers ${ }^{3-6}$ as the mortality rate due to cancer continues to rise. ${ }^{7}$ Despite several advancements in conventional treatment, such as surgery, chemo and radiation therapy, the progress of research in this area still requires new initiatives. Recent advances in drug delivery have

${ }^{a}$ Institute of Bioproduct Development, Department of Bioprocess Engineering, Faculty of Chemical and Energy Engineering, Universiti Teknologi Malaysia, Skudai 81110, Johor Bahru, Johor, Malaysia

${ }^{b}$ Advanced Materials Research Centre, Department of Materials Engineering, Islamic Azad University, Najafabad Branch, Najafabad, Iran

'Institute of Marine Biotechnology, Universiti Malaysia Terengganu, Kuala Terengganu, Malaysia

${ }^{d}$ Department of Analytical Chemistry, University of Tehran, Tehran, Iran

${ }^{e}$ Institute of Bioproduct Development, Universiti Teknologi Malaysia, Skudai 81110, Johor Bahru, Johor, Malaysia

† Electronic supplementary information (ESI) available. See DOI: 10.1039/c7ra06389j greatly improved the pharmacokinetics and dynamics of the drugs in addressing some of the issues the current drugs have with poor bioavailability, stability and high systemic toxicity. ${ }^{8-10}$

In spite of these advances, immune clearance as well as difficulties in achieving effective concentration and targeted selectivity remain challenging and demanding. ${ }^{11-13}$ The last few years have witnessed the development of a number of nanoparticles-based therapeutic agents for various diseases as these offer several advantages, such as longer circulation time, enhanced permeability and retention (EPR), and improved bioavailability of drugs. ${ }^{\mathbf{1 4 , 1 5}}$ Some studies carried out recently showed that SPIONs are rewarding magnetic nanoparticles possessing superb characteristics; for instance, recent studies have shown that RBC membrane-coated SPIONs could resist the immune response as well as have rapid clearance in the body, which is known as a major challenge in nanomedicine. ${ }^{\mathbf{1 6 , 1 7}}$

In the current era, it is essential and also crucial to develop sensitive, specific, and accelerated methods for the diagnosis and therapy of cancer since it is a serious concern in the international community and the current treatments utilized are insufficient. ${ }^{\mathbf{1 8} 19}$ Recent advances in nanotechnology have 
introduced ultrasmall platforms, such as superparamagnetic iron oxide nanoparticles (SPIONs), which invaluably offer an improvement in cancer therapy, such as targeted drug delivery, ${ }^{20}$ magnetic tumor-targeting hyperthermia, ${ }^{21}$ various localized therapies, ${ }^{22}$ cell labeling, ${ }^{23}$ cell tracking, ${ }^{24}$ magnetic resonance imaging, ${ }^{25-27}$ and photothermal therapy. ${ }^{28}$ Cengelli et $a{ }^{29}{ }^{29}$ coated fluorescent SPIONs with PEG and then immobilized a fluorescent reporter molecule, and then administered the system to a microglial cell culture containing nervous system immune cells, where the results obtained proved that the engineered SPIONs possessed satisfying biocompatibility as well as remarkable intracellular uptake. In another study, ${ }^{30}$ magnetite nanoparticles were loaded with doxorubicin and then conjugation of an antibody to the drug was carried out, and the combination made was then used for simultaneous cancer diagnosis and therapy. The results showed the sustainable release of encapsulated doxorubicin with no inhibition due to presence of the magnetic nanocapsules. Kubo et al. ${ }^{31}$ performed implantation of permanent magnets in the sites of hamster solid osteosarcoma and carried out the delivery of cytotoxic compounds through magnetic liposomes, whereby cytotoxic drug delivery was increased by a factor of four times in comparison with conventional intravenous (nonmagnetic) delivery. ${ }^{31}$ Moreover, a remarkable increase in anti-tumor activity was seen and weight-loss as a side effect was eliminated. ${ }^{32}$ In 2011, Yoo et al. ${ }^{33}$ used folic acid and cy5.5 to functionalize SPIONs in order for them to be used in the lungcancer-targeted optical imaging of lung cancer, where stronger optical imaging was observed in the lung cancer model. In 2011, another study showed good intracellular drug distribution and interaction for doxorubicin-SPIONs on MCF-7 cells in comparison with a solution of neat doxorubicin. ${ }^{34}$ Recently, Nasiri et $a l^{35}$ showed that the cytotoxic effect was improved in papain-conjugated cobalt ferrite nanoparticles compared to neat papain. Similarly, Mosafa et al. ${ }^{36}$ demonstrated the identical characteristics of papain-immobilized magnetic nanoparticles compared with neat papain.

Nowadays, SPIONs have been preclinically studied and studies are now beginning with clinical trials. ${ }^{25,37}$ Various routes are available for SPIONs synthesis, such as sono-chemical synthesis, emulsion, thermal decomposition, co-precipitation, and hydrothermal synthesis. ${ }^{38,39}$ Co-precipitation is known as a simple and reliable method to synthesize SPIONs with diameters $<20 \mathrm{~nm}^{40}$ SPIONs have been lately found to be highly potent to perform as a drug-delivery vehicles, since they are poorly toxic ${ }^{\mathbf{4 1}}$ and possess a sufficient amount of magnetic saturation. ${ }^{42}$ Our previous study ${ }^{43}$ showed that the conjugation of folic acid (FA) to citrate-coated SPIONs could enable the fabrication of a novel complex possessing the ability to target the FAR+ cancer cells ${ }^{43-47}$ while possessing remarkably biocompatibility. ${ }^{43}$

In recent years, a variety of naturally occurring dietary compounds have been shown to possess significant anticancer properties. ${ }^{48}$ Among these, bromelain (EC 3.4.22.33), a cysteine proteinase derived from pineapple (Ananas comosus), has been used for several therapeutic applications, such as the inhibition of platelet aggregation, as an anti-inflammatory agent, in modulation of cytokines, in enhancing the absorption of antibiotics, and as an anti-tumor activity agent. ${ }^{49-51}$ Bromelain (Br) is known as an effective anticancer phyto-therapeutic agent. The acceptance of $\mathrm{Br}$ as a phyto-therapeutical drug among researchers is now increasing because of its higher efficacy and non-toxic nature. ${ }^{52}$ Also, it was found that the beginning of tumorigenesis was delayed while the number of tumors were reduced due to pre-treatment with $\mathrm{Br}$ in a mouse skin cancer model. ${ }^{49}$ In Central and South America, pineapple has been known as a folk medicine for centuries. The plant's medicinal properties are related to bromelain, which is an extract from the stem of the pineapple that has been marketed for the last six decades. ${ }^{51}$ Bromelain's multiple constituents are the reason why it is medicinally beneficial; for instance, $\mathrm{Br}$ contains proteolytic enzymes comprising sulfhydry ${ }^{53}$ as well as peroxidase, escharase (a nonproteolytic component with debriding effects), glucosidases, acid phosphatase, several protease inhibitors, cellulases, carbohydrates, organically bound calcium and glycoproteins. ${ }^{52,54}$ Bromelain has proved its capabilities to affect physiological processes, such as coagulation, inflammation, and the immune response. Hence, through preclinical and clinical studies, the therapeutic effects of bromelain either alone or in combination with other therapeutics have been evaluated, and has indicated some clinical benefits. ${ }^{55}$ It was revealed that the anticancer activity of bromelain may be due to the protease components it possesses. ${ }^{56}$ To apply effectively, it is necessary to find a new approach for targeting the delivery of $\mathrm{Br}$, and also to enhance $\mathrm{Br}$ concentration at the tumor site. In the past few years, the complete release of native protein from orally delivered carrier systems has become a major problem due to a high probability of protein degradation and instability. Proteins are therapeutically inactive while aggregated or denatured and can cause unforeseeable side effects, including toxicity and immunogenicity. Our previously published study ${ }^{\mathbf{4 3}}$ showed that bromelain possesses remarkable anticancer effects on ovarian and colon cancer cell lines, but it had toxic effects toward normal cell lines. So, synthesizing a safe targetable delivery system to minimize the side effects of bromelain on normal cell lines and to maximize their toxic effect on tumor site is highly required.

In this study, the synthesis, characterization, and evaluation of dual-functional nanocarrier (SPIONs-Br-FA) for the delivery of anticancer agents, namely bromelain, was investigated. Nobody has tried the nano-delivery of bromelain using $\gamma-\mathrm{Fe}_{2} \mathrm{O}_{3}$ to the FAR+ cancer cells before this, but, in this study, Br was conjugated to the citrate SPIONs and finally it was targeted to the FAR+ cancer cells using FA resulting in the synthesis of a novel biocompatible dual-functional therapeutic biomaterial with desired characteristics. The anti-tumor efficacy of the formulated SPIONs-Br-FA in different cancer cell lines was measured and in vivo studies were user to evaluate the efficacy in the 4T1-bearing Balb/C mice model.

\section{Materials and methods}

\section{Materials}

The chemicals utilized in the current research were all analytically pure, including sulfuric acid $\left(\mathrm{H}_{2} \mathrm{SO}_{4}\right)$ (QRëC), iron(II) 
chloride $\left(\mathrm{FeCl}_{2}\right)$ (99\% purity, Sigma Aldrich), iron(III) chloride $\left(\mathrm{FeCl}_{3}\right)$ (45\% purity, Riedel-de Haen), acetone (QRëC), hydrochloric acid ( $\mathrm{HCl})$ (37\% purity, QRëC), folic acid (Sigma Aldrich), potassium bromide (KBr, Sigma Aldrich), $\mathrm{N}$-ethyl- $\mathrm{N}$-(3dimethylaminopropyl)carbodiimide hydrochloride (EDC, 99\% purity, Sigma Aldrich), N-hydroxy succinimide (NHS, 98\% purity, Sigma Aldrich), bovine serum albumin (BSA, Sigma Aldrich), Bradford Reagent (Sigma Aldrich), bromelain (Merck), HSF 1184 cell line (human skin fibroblast cell line, ATCC Manassas, VA), HeLa cell line (human cervical cancer cell, ATCC Manassas, VA), MDA-MB-468 cell line (human breast cancer cell, ATCC Manassas, VA), MDA-MB-231 cell line (human breast cancer cell, ATCC Manassas, VA), $4 \mathrm{~T} 1$ cell line (animal stage IV human breast cancer cell, ATCC Manassas, VA), fetal bovine serum (Gibco, USA), trypsin EDTA (Gibco, USA), phosphate buffered saline (PBS, Gibco, USA), MES sodium salt (MES, Sigma Aldrich), Dulbecco's modified eagle's medium (DMEM, Gibco, USA), RPMI medium 1640 (Gibco, USA), penicillinstreptomycin (Gibco, USA), dimethyl sulfoxide (DMSO, Sigma Aldrich), thiazolyl blue tetrazolium bromide (MTT, Sigma Aldrich), Prussian blue test kit (Sigma Aldrich), cisplatin (Sigma Aldrich), paraformaldehyde (Sigma Aldrich), and osmium tetroxide solution (Sigma Aldrich). In all the experiments, water was previously deionized (18 M $\Omega$ ). Moreover, 5 week-old female $\mathrm{Balb} / \mathrm{C}$ mice and all their requirements were procured from Bistari Co., Malaysia.

\section{Preparation of the activated SPIONs-COOH core material}

Maghemite nanoparticles were fabricated through a coprecipitation method described in our previous study. ${ }^{43}$ In brief, a solution of ferric chloride and ferrous chloride was mixed with ammonium hydroxide. The resultant magnetites were magnetically separated and washed via deionized water. The excess base was then removed using a solution of nitric acid in order to accomplish the neutralization of the precipitate. Then, oxidization of the obtained magnetites to maghemites was performed by adding ferric nitrate at $100{ }^{\circ} \mathrm{C}$ for $0.5 \mathrm{~h}$. Subsequently, washing of the precipitate with acetone was carried out prior to the product being finally dispersed in water to obtain stable $\gamma-\mathrm{Fe}_{2} \mathrm{O}_{3}(\mathrm{pH}=7)$. After the maghemite synthesis, $50 \mathrm{ml}$ of ferrofluid sample was added to $5 \mathrm{~g}$ of CA dissolved in $10 \mathrm{ml}$ DI-water initially and the temperature was raised to $90{ }^{\circ} \mathrm{C}$ under continuous stirring for $90 \mathrm{~min}$. The mixture was cooled down to room temperature until blackish precipitates were observed. The procedure was continued by washing using acetone to acquire citric acid-coated SPIONs (SPIONs-COOH). ${ }^{43,57}$ The final product was named SPIONs$\mathrm{COOH}$.

\section{Bromelain conjugation}

Conjugation of the bromelain to the coated SPIONs was performed through the EDC/NHS click chemistry reaction..$^{58-60}$ In brief, a mixture of $\mathrm{N}$-ethyl- $\mathrm{N}$-(3-dimethylaminopropyl)carbodiimide hydrochloride (EDC) and $N$-hydroxysuccinimide (NHS) in MES buffer $(0.05 \mathrm{M}, \mathrm{pH}=5.7)$ was added to $5 \mathrm{ml}$ of activated SPIONs-COOH and mixed at ambient temperature for $1.5 \mathrm{~h}$.
Then, the resulting solution underwent a careful two-fold washing via phosphate buffer solution (PBS), $\mathrm{pH}=7.4$, and removal of the aqueous layer was carried out afterwards. Bromelain $\left(27 \mathrm{mg} \mathrm{ml}^{-1}\right.$, in $\left.5 \mathrm{ml} \mathrm{PBS}, \mathrm{pH}=7.4\right)$ was then mixed with the activated SPIONs-COOH and the mixture was stirred for the next $3 \mathrm{~h}$. Then, the reaction was quenched through the addition of $25 \mathrm{mM}$ glycine in PBS for $0.5 \mathrm{~h}$ with continuous stirring. Washing was performed three times using PBS, until finally the suspension of the final product (SPIONs-Br) was ready for further use.

\section{Determination of the amount of conjugated bromelain}

The amount of bromelain conjugated onto the nanoparticles was determined by measuring the initial and final concentrations of bromelain using the Bradford method, in which Coomassie protein assay reagent was used while BSA was used as the standard. ${ }^{61}$

\section{Folic acid conjugation and loading content determination}

Folic acid (FA) was conjugated to the SPIONs-Br and then the FA loading content was determined using the same method as described in Nasiri et $a l .{ }^{43}$ The final resulting nanocarriers were called SPIONs-Br-FA.

\section{Characterization}

The size of the obtained samples was evaluated using transmission electron microscopy (TEM) (Hitachi H-7500), where analysis of the snapshots assisted approximating the nanoparticles' diameters. Field emission scanning electron microscopy (FESEM, JSM-6700F, JEOL, Tokyo, Japan) was carried out to evaluate the morphology of the samples. The accelerating voltage was $5 \mathrm{kV}$, while the working distance between the detector and the samples was $1.5 \mathrm{~cm}$. Subsequently, the snapshots obtained were transformed to $3 \mathrm{D}$ images using $\mathrm{NIH}$ Image J software (1.46r/Java 1.6.0_20 (32 bit)).

The chemical integrity was investigated afterward using Fourier Transform Infrared Spectroscopy (FT-IR) spectra analysis in the range of $400-4000 \mathrm{~cm}^{-1}$.

The hydrodynamic diameters and surface zeta potential were gauged using a Nano Zetasizer particle-sizing instrument (Malvern Instruments, Malvern, UK) after the nanoparticles powder was diluted in deionized distilled water. Equilibration of the samples was performed at $25{ }^{\circ} \mathrm{C}$ for 5 min prior to each measurement.

Atomic absorption spectroscopy (SpectrAA-10 Plus spectrometer, Varian, France) at $248.3 \mathrm{~nm}$ was used to determine the iron concentration in the samples.

The changes in the chemical and physical characteristics of the samples were measured using thermogravimetric analysis (TGA) via a thermogravimetric analyzer (Shimadzu, model TG50) under certain adjustments: heating rate of $10{ }^{\circ} \mathrm{C} \mathrm{min}^{-1}$, $\mathrm{N}_{2}$ flowing rate of $50 \mathrm{ml} \mathrm{min}^{-1}$, and temperature ranging from $25{ }^{\circ} \mathrm{C}$ to $800{ }^{\circ} \mathrm{C}$.

Verification of the crystalline structures was performed via $\mathrm{X}$ ray diffraction using a Panalytical X'PERT MPD X-ray diffractometer. The diffractometer was equipped with a copper anode 
that could generate high intensity $\mathrm{Cu} \mathrm{K} \alpha$ radiation $(\lambda=1.54065$ $\AA)$. The range of $2 \theta$ was between $10^{\circ}$ and $90^{\circ}$.

\section{Anti-coagulation assay}

A semi-automated blood coagulation analyzer Clot SP was employed to determine the pro-thrombin time (PT), thrombin time (TT), and the activated partial thromboplastin time (APTT) of human blood incubated with samples for intrinsic, extrinsic, and both intrinsic and extrinsic pathways, respectively. The fibrinogen formation time (FB) of the samples was also measured using the same device. The blood sample was obtained from a male donor (29 years old, no history of extreme disease) at the Health Centre of Universiti Teknologi Malaysia (UTM) and transferred to the tube containing citrate to avoid the blood sample from coagulating. Informed consent was obtained from the donor for the use of their blood and the dissemination of information about their blood in the scientific record. The procedure was accepted as satisfactory by the Medical Advisory Committee and the Clinical Ethics Committee of Sultanah Aminah Healthcare Hospital Berhad, Malaysia, in association with the Ministry of Health ( $\mathrm{MOH})$. PBS solution $(\mathrm{pH}=7.4)$ was used to dilute the samples $(0.2 \mathrm{ml})$ and the diluted samples were incubated together with $500 \mu \mathrm{l}$ plasma of fresh human blood under specific conditions: $30 \mathrm{~min}, 37^{\circ} \mathrm{C}$, and in a transparent plastic tube. Eventually, the PT, TT, APTT, and FB were measured three times for each of the samples. ${ }^{62}$ In order to carry out the hemolysis study, $100 \mu \mathrm{l}$ of washed RBCs together with $900 \mu \mathrm{l}$ of each of the samples dispersed in saline was incubated for $2 \mathrm{~h}$, followed by centrifugation for $5 \mathrm{~min}$ at $1500 \mathrm{rpm}$. Subsequently, to the collected supernatant, $900 \mu \mathrm{l}$ of saline was added and via a UV spectrophotometer (Carywin UV), the absorbance was recorded at $541 \mathrm{~nm}$. The coagulation test in a slide method was carried out to determine the hard clot formation time on slide. The synthesized samples were diluted in $0.2 \mathrm{ml}$ of phosphate buffered saline (PBS) solution ( $\mathrm{pH}=7.4$ ). The samples were incubated with a drop of blood on the glass slide at $37^{\circ} \mathrm{C}$. Every $30 \mathrm{~s}$, the needle was placed in the middle of a blood drop and it was then elevated. Blood coagulation started when fibrin threads appeared attached to the needles. Through manually dipping a silicon-coated stainless steel hook into the solution, hard clot formation was closely monitored via the detection of fibrin threads. Clotting time was recorded once the first fibrin formation sign was seen, and the clotting time was recorded. In order to obtain reliable values, each test was repeated three times (with hard clot formation normally taking place in 5 to $10 \mathrm{~min}$ ).

\section{Cell lines}

The HSF 1184 (normal human skin cell line), HeLa (human ovarian cancer cell line, FAR+), MDA-MB-468 (human breast cancer cell line, FAR-), MDA-MB-231 (human breast cancer cell line, FAR+), and 4T1 (animal stage IV breast cancer cell line, FAR+) cell lines were purchased from ATCC. The HSF 1184, MDA-MB-231 and MDA-MB-468 cell lines were both cultured in DMEM medium supplemented with $10 \%$ fetal bovine serum (VWR, Visalia, CA) and 1\% penicillin-streptomycin (Sigma, St.
Louis, MO). HeLa and 4T1 cell lines were cultured in RPMI 1640 medium with $10 \%$ fetal bovine serum (VWR, Visalia, CA) and $1 \%$ penicillin-streptomycin (Sigma, St. Louis, MO). Cells were maintained at $37 \pm 0.5{ }^{\circ} \mathrm{C}$ in a humid atmosphere of $5 \% \mathrm{CO}_{2}(\mathrm{v} /$ v) in air. All the tests were accomplished when the cells were in their exponential growth phase.

\section{Anti-proliferation assay}

Tetrazolium dye (MTT) assay was carried out for evaluation of the viability of HSF 1184, HeLa, MDA-MB-468, MDA-MB-231, and $4 \mathrm{~T} 1$ cell lines when they are treated with bare SPIONs, SPIONs-COOH, SPIONs-FA, neat Br, SPIONs-Br, and SPIONs$\mathrm{Br}-\mathrm{FA} .{ }^{63}$ After being harvested, the cells were resuspended in their related medium at $5 \times 10^{4}$ cells $/ 200 \mu \mathrm{l}$. Subsequently, 24well plates were used to culture the cells. After $24 \mathrm{~h}$, the medium of each cell line was removed and replaced with $200 \mu \mathrm{l}$ of each sample $\left(100,200,300,500,1000 \mu \mathrm{g} \mathrm{ml}^{-1}\right)$ diluted with medium and located in an incubator for $24 \mathrm{~h}$. Then, $20 \mu \mathrm{l}$ of MTT ( $5 \mathrm{mg}$ $\mathrm{ml}^{-1}$ ) was added prior to $4 \mathrm{~h}$ incubation in absolute darkness since this reaction is highly sensitive to light. Subsequently, the formulations were aspirated prior to the addition of $200 \mu \mathrm{l}$ of DMSO in order for formazan crystals to be dissolved. Afterwards, measurement of the absorbance at $570 \mathrm{~nm}$ was carried out via a microplane reader (BioRad). The medium was used as blank while untreated cells were used as the control with $100 \%$ viability. Finally, the results are expressed herein as mean values \pm standard deviation of 6 independent measurements. Compared to the control group, the relative cell viability (\%) was calculated via eqn (1).

$$
\text { Cell viability }(\%)=\frac{\text { OD } 570(\text { sample })}{\text { OD } 570(\text { control })} \times 100
$$

\section{Morphological assessment by phase-contrast inverted microscopy}

The morphological apoptosis of cells after treatment with neat $\mathrm{Br}$ and SPIONs-Br-FA was observed using an inverted microscope according to the standard protocol. ${ }^{64} \mathrm{~A}$ solution of $1 \times 10^{5}$ cells per $\mathrm{ml}$ was seeded in 6-well plates and the cells were treated for $24 \mathrm{~h}$ with neat $\mathrm{Br}$ (at the $\mathrm{IC}_{50}$ value) and SPIONs-Br$\mathrm{FA}$ (at the $\mathrm{IC}_{50}$ value of neat $\mathrm{Br}$ ), with a $70 \%$ level of confluence achieved. The negative control was the untreated cells, while cisplatin was used as the positive apoptosis control. Next, removal of the medium and washing with PBS were carried out so as to track the morphological alterations occurring.

\section{Apoptosis detection by AO/EB staining}

Slight modifications were made to Acridine orange (AO) and ethidium bromide (EB) double staining as described by Gani et al. ${ }^{65}$ The cells were treated with neat $\mathrm{Br}$ (at the $\mathrm{IC}_{50}$ value) and SPIONs-Br-FA (at the $\mathrm{IC}_{50}$ value of neat $\mathrm{Br}$ ) for $24 \mathrm{~h}$. After $24 \mathrm{~h}$ treatment, using $100 \mu \mathrm{l}$ of $1 \times$ working solution, the cells were stained. $1 \times$ working solution was prepared by mixing $500 \mu \mathrm{g}$ EB and $100 \mu \mathrm{g}$ AO in $1 \mathrm{ml}$ of PBS. Once the cells had undergone a 10 min incubation, the cells were observed using a fluorescent 
microscope (Olympus). The nuclei of the living cells were stained green once with $\mathrm{AO}$, which was used as a cell-permeant dye. Unlike the AO, in cells with ruptured plasma membranes or dead cells, the nuclei were stained orange through EB staining. As a result, live cells with an organized structure were observed in green, while the dead cells with round nuclei were observed in orange. From at least 200 cells, the number of viable, apoptotic, and necrotic cells were counted. The percentages of apoptotic and necrotic cells were then calculated using eqn (2) and (3), respectively,

$$
\begin{aligned}
& A_{\text {cell }}(\%)=\frac{N_{\mathrm{a}}}{N_{\mathrm{t}}} \times 100 \\
& N_{\text {cell }}(\%)=\frac{N_{\mathrm{n}}}{N_{\mathrm{t}}} \times 100
\end{aligned}
$$

where $A_{\text {cell }}(\%)$ stands for the percentage of apoptotic cells, $N_{\text {cell }}$ (\%) stands for the percentage of necrotic cells, $N_{\mathrm{a}}$ is the number of apoptotic cells, $N_{\mathrm{n}}$ represents the number of necrotic cells, and $N_{\mathrm{t}}$ is the total number of cells.

\section{Scratch motility assay}

In order to measure the ability of the FAR+ cells treated with neat $\mathrm{Br}$ (at the $\mathrm{IC}_{50}$ value) and SPIONs-Br-FA (at the $\mathrm{IC}_{50}$ value of neat $\mathrm{Br}$ ), a scratch assay was performed according to Amini et al. ${ }^{64}$ with slight modifications. Briefly, in a 6-well plate, $3 \times$ $10^{5}$ cells per well were seeded and incubated to obtain a confluent monolayer. Using a cell scrapper, the monolayer was linearly scratched and the debris and the detached cells were removed after being gently washed via PBS. Next, treatment of the cells via neat $\mathrm{Br}$ and SPIONs-Br-FA was performed. The negative control wells were filled using the complete medium and incubated at $37^{\circ} \mathrm{C}$, while the migrated distance by the cells was measured at 0,12 , and $24 \mathrm{~h}$ using an inverted phasecontrast microscope (Zeiss Axiovert 100). For evaluation and comparison of the width of the scratches at each time interval, NIH Image J software was operated. Statistical calculations were performed to obtain the healing rates, while the final results were released as cell migration percentages.

\section{Clonogenic inhibition assay}

Previously, a clonogenic cell survival assay was performed as described by Gani et al. ${ }^{65}$ with slight modifications. In brief, cells in their growth log phase were trypsinized. Then, a triplicate seeding of almost $1 \times 10^{3}$ cells per ml into 6 -well plates was performed and the medium was replaced by a medium containing neat $\mathrm{Br}$ (at the $\mathrm{IC}_{50}$ value) and SPIONs-Br-FA (at the $\mathrm{IC}_{50}$ value of neat $\mathrm{Br}$ ) a day later. A day later, fresh medium replaced the extracts and the cells were maintained at $37{ }^{\circ} \mathrm{C}$ in ${\mathrm{a} \mathrm{CO}_{2}}$ incubator for 10 days, during which growth media were refreshed every 2 days. Fixation of the colonies was carried out using $-20{ }^{\circ} \mathrm{C}$ methanol and staining with $0.5 \%$ trypan blue solution. The results were then expressed as q colony-formingpotential percentage for the colonies including 50 or more cells. Eqn (4) was used to calculate the efficiency of the colony formation:

$$
\eta_{\text {c.f }}=\frac{N_{\mathrm{c}}}{N_{\mathrm{i}}} \times 100 \%
$$

where $\eta_{\text {c.f }}$ is the colony formation efficiency, $N_{\mathrm{c}}$ is the number of the colonies formed, and $N_{\mathrm{i}}$ is the number of cells incubated.

\section{In vivo analysis}

Animal handling and establishing the 4T1-bearing mice model. The Institutional Review Board of the Universiti Kebangsaan Malaysia Animal Ethics Committee (UKMAEC), Selangor, Malaysia, approved this study and granted its ethical endorsement (UTM/2014/ANI/26 NOV/625). A submitted full research proposal, an interview, and hands-on animal training session were required for the ethical clearance. Data collection was performed at the Universiti Teknologi Malaysia as the housing location. Therefore, according to the rules and regulations set by the UKMAEC, proper handling of all the experimental protocols were carried out.

The maintenance of the 15 to $20 \mathrm{~g}$ and 6 week-old female Balb/C mice were carried out using wood shavings-bedded polypropylene cages at ambient temperature, while the mice had unlimited access to water and a folate-deficient diet over the course of the experiment in order to decrease the level of folic acid to the minimum, ${ }^{66}$ while a $12 \mathrm{~h}$ light/dark cycle was applied. The adaptation period was considered to be 7 days. Female Balc/C mice were each subcutaneously injected with $1 \times$ $10^{6} 4 \mathrm{~T} 1$ murine mammary carcinoma cells $(n=6)$ into the mammary fat pad for establishment of the mice bearing the breast cancer tumor. Two to three weeks later, the 4T1-injected mice with palpable primary tumors were observed.

The standard protocol of H\&E staining was followed to confirm the presence of tumor cells under an inverted microscope (Nikon Eclipse Ti-s examination). ${ }^{67}$ In brief, tissue removal was carried out upon necropsy and the removed tissue underwent fixation in formalin (10\%). Subsequently, the processed tissues were paraffin-embedded, sectioned at $5 \mu \mathrm{m}$, located on glass slides, and stained via hematoxylin and eosin through standard procedures.

Quantitative biodistribution study in the 4T1-bearing mice model. A quantitative biodistribution study was carried out according to ref. 68 and 69, with slight modification. The 4T1bearing mice were injected via the tail vein with $100 \mu \mathrm{l}$ of SPIONs-COOH and SPIONs-FA $\left(10 \mathrm{mg} \mathrm{kg}^{-1}\right)$ and sacrificed at 4 , 12 , and $24 \mathrm{~h}$ time points. The blood was collected by cardiac puncture and, after euthanasia, the heart, liver, spleen, lungs, kidneys, stomach, muscle, and tumor were collected, weighed, and dissolved completely by adding $2 \mathrm{ml}$ of $\mathrm{HCl}$ and $1 \mathrm{ml}$ of $\mathrm{HNO}_{3}$ at $70{ }^{\circ} \mathrm{C}$ for $6 \mathrm{~h}$. The solution was diluted with deionized water and filtered with a $0.45 \mu \mathrm{m}$ Teflon filter. The sample was analyzed for iron by atomic absorption spectroscopy (AAS) (VARIAN, model AA240FS). The uptakes of the nanoparticles in the organs were calculated as a mean percentage of the injected doses per gram of organ tissues (\% ID per g). Each sample and time point included six independent repetitions.

Qualitative biodistribution studies in the 4T1-bearing mice model. Qualitative biodistribution studies in the 4T1-bearing mice were performed by TEM. The 4T1-bearing mice were 
Table 1 First group in the in vivo study

\begin{tabular}{lll}
\hline Group I & Saline & \\
Group II & SPIONs-COOH & $10 \mathrm{mg} \mathrm{kg}^{-1}$ \\
Group III & Neat Br & $10 \mathrm{mg} \mathrm{kg}^{-1}$ \\
Group IV & SPIONs-Br & $4 \mathrm{mg} \mathrm{kg}^{-1}$ \\
Group V & SPIONs-Br & $8 \mathrm{mg} \mathrm{kg}^{-1}$ \\
Group VI & SPIONs-Br & $10 \mathrm{mg} \mathrm{kg}^{-1}$
\end{tabular}

Table 2 Second group in the in vivo study

\begin{tabular}{|c|c|c|}
\hline Group I & Saline & \\
\hline Group II & SPIONS-FA & $8 \mathrm{mg} \mathrm{kg}^{-1}$ \\
\hline Group III & SPIONs-Br-FA & $8 \mathrm{mg} \mathrm{kg}^{-1}$ \\
\hline Group IV & $\begin{array}{l}\text { SPIONs-Br-FA + coinjection } \\
\text { of excess folic acid }\end{array}$ & $8 \mathrm{mg} \mathrm{kg}^{-1}$ \\
\hline Group V & SPIONs-Br & $8 \mathrm{mg} \mathrm{kg}^{-1}$ \\
\hline Group VI & $\begin{array}{l}\text { Neat bromelain } \\
\text { (at the same concentration of } \mathrm{Br} \text { in } \\
\text { conjugated nanoparticles } \sim 1 \mathrm{mg} \mathrm{kg}^{-1} \text { ) }\end{array}$ & \\
\hline
\end{tabular}

injected via the tail vein with $100 \mu \mathrm{l}$ of SPIONs-FA $\left(10 \mathrm{mg} \mathrm{kg}^{-1}\right)$ and sacrificed at $24 \mathrm{~h}$ after injection. To verify the SPIONs-FA biodistribution in the major organs, including the heart, liver, spleen, lungs, kidneys, stomach, muscle, and tumor, these tissues were collected and washed with PBS. These tissues were fixed using paraformaldehyde (10\%) and were paraffin-embedded. Using an ultramicrotome, the sections were prepared in an ultrathin manner. Then, the ultrathin sections were mounted on 200 mesh copper grids stained with $2 \%$ osmium tetroxide (dissolved in distilled water) for $30 \mathrm{~min}$ according to the standard procedure. $^{70}$ All the stained sections were observed under a Hitachi HT7700 Bio-Medical TEM microscope.

\section{In vivo anticancer efficacy}

The anticancer efficacy of SPIONs-Br and SPIONs-Br-FA were evaluated in the 4T1-bearing mice model compared with neat $\mathrm{Br}$. Mice were inoculated with $1 \times 10^{6}$ cells per mouse on day 0 , followed by treatment with neat $\mathrm{Br}$ and nanoparticles in different formulations after $24 \mathrm{~h}$ post inoculation of the $4 \mathrm{~T} 1$ cancer cells. The mice were randomly divided into 6 groups of 6 as shown in Table 1 (note: after getting the in vivo anticancer efficiency results of the first group, the second group of 4T1bearing mice model were randomly divided into 6 groups of 6 , as shown in Table 2). The same procedure was followed for the second group of study.

The formulations were administered intravenously three times a week to the 4T1-bearing mice model. Mice of the control groups were treated with the same volume of normal saline. The tumor volume was measured every other day in all the groups.

The diameter of each tumor was measured using a digital caliper. The obtained readings were used in order to calculate the tumor size through eqn (5), whereby the effect of the treatment was assessed:

$$
v=\frac{1}{2} a b^{2}
$$

where $v$ is tumor volume, $a$ is the longest diameter, and $b$ is the shortest diameter.

Additionally, the survival rate was calculated using eqn (6):

$$
R_{\text {sur }}=\frac{N_{\text {sur }}}{N_{\mathrm{t}}}
$$

where $R_{\text {sur }}$ is the survival rate, $N_{\text {sur }}$ is the number of surviving mice, and $N_{\mathrm{t}}$ is the total number of mice.

\section{Statistical analysis}

The data were analyzed by one or two-factor ANOVAs with appropriate post-tests as well as multiple $t$-test analysis using GraphPad Prism software (version 6.0). The obtained results are reported herein as the mean \pm S.E.M (standard error of the mean) of at least three independent experiments. Statistically significant data were the ones with a $p$-value $<0.05$.

\section{Results and discussion}

\section{Synthesis and characterizations}

The major goal of the present study was to synthesize, characterize, and evaluate the biocompatibility, binding, and anticancer efficacy of exquisite SPIONs-Br-FA in vitro and in vivo. Fig. 1 illustrates a schematic representation of the study design. Fig. 1(A) shows the functionalization of the dual-functional SPIONs-Br-FA. Fig. 1(B) illustrates the in vitro targeting efficiency of the folate-conjugated SPIONs, which is significantly higher in FAR+ cells (HeLa, MDA-MB-231 and 4T1) compared to in the FAR - cells (HSF 1184 and MDA-MB-468), while Fig. 1(C) shows the in vivo effectiveness of SPIONs-Br-FA in the inhibition of cancer growth compared to the SPIONs-Br and neat $\mathrm{Br}$. The step-by-step synthetic routes for the CA-coated SPIONs and $\mathrm{Br}$ and FA conjugation are shown in Fig. 2. Initially, the synthesized SPIONs were stabilized via citric acid, as shown in Fig. 2(A), followed by Br conjugation through the EDC/NHS click chemistry method, as shown in Fig. 2(B1) and (B2). The reaction was followed by FA immobilization of the Br-conjugated SPIONs, as shown in Fig. 2(C) in order to facilitate the targeting efficiency of Br-conjugated SPIONs to different types of cancers, such as breast, lung, and cervical, in which the overexpression of the folate receptor is seen. ${ }^{71-74}$

We previously reported that FA provides a good cancer cellspecific target in vitro. ${ }^{43}$ Here, we present the modification of targetable nanoparticles by the conjugation of $\mathrm{Br}$ (anticancer agent) to the activated SPIONs-COOH, which serves as a bromelain $(\mathrm{Br})$ delivery vehicle to the FAR+ cancer cells. Furthermore, the effectiveness of the final engineered formulation (SPIONs-Br-FA) was investigated with cancer cells (HSF 1184, MDA-MB-468, MDA-MB-231, and HeLa) and the 4T1bearing mice model, respectively.

TEM and FESEM observations (Fig. 3) revealed that the functionalized SPIONs (SPIONs-Br-FA) were spherical and nearly uniform (Fig. $3\left(\mathrm{a}_{3}\right)$ and $\left(\mathrm{c}_{1}\right)$ ), with an average diameter size of approximately 23-24 nm (Fig. 3( $\left.\mathrm{c}_{3}\right)$ ). Moreover, the morphology undergoes slight alterations after functionalization (Fig. 3( $\left.b_{1}\right)$ and $\left(c_{1}\right)$ ) and nanoparticles tend to grow as shown in 

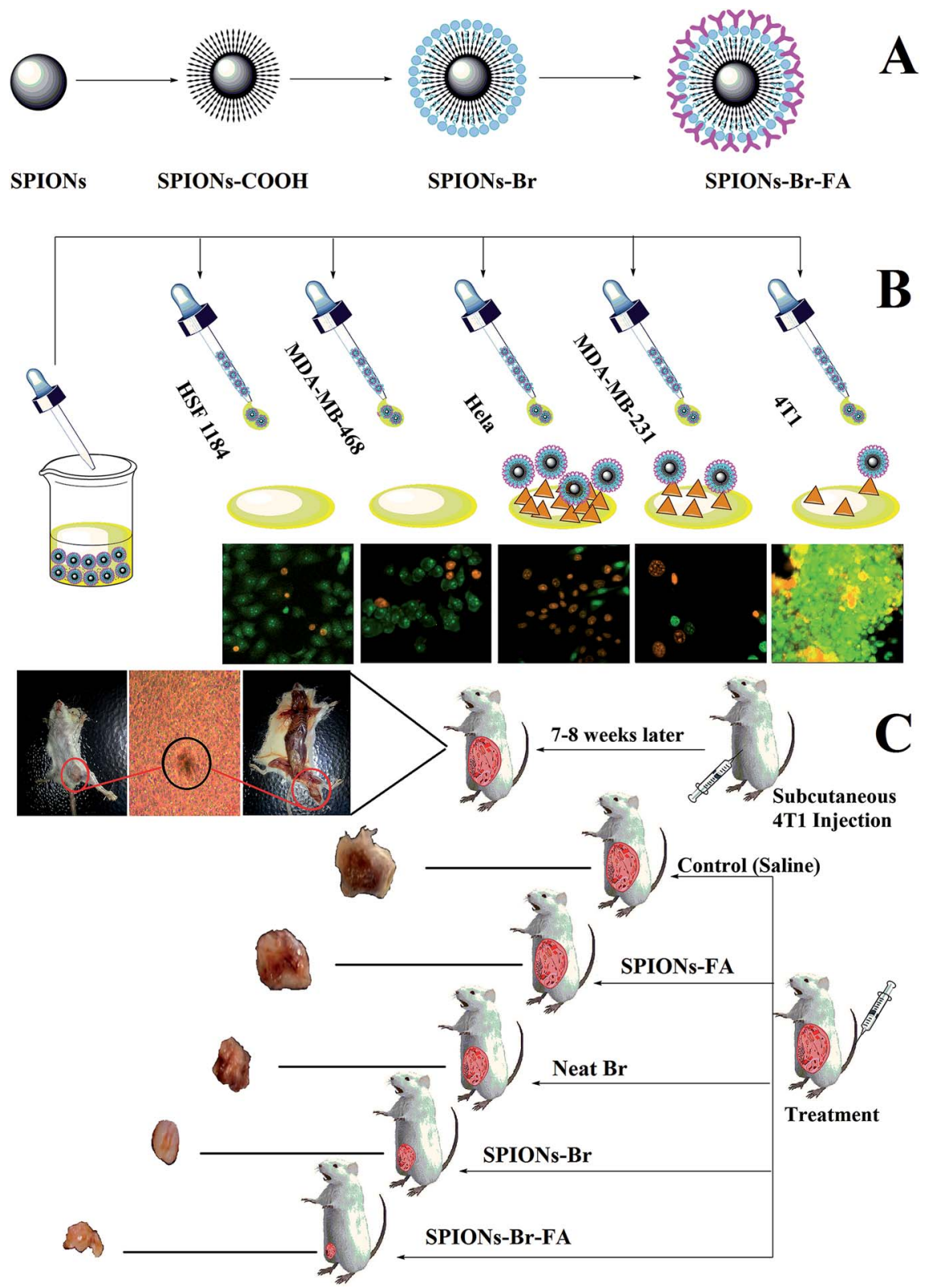

Fig. 1 (A) Schematic presentation of the functionalization of dual-functional SPIONs-Br-FA, (B) SPIONs-Br-FA binding to the FA receptors on the cancer cells, (C) administration of SPIONs with different formulations into the 4T1-bearing mice model, leading to the inhibition of cancer growth.

the size distribution graph (Fig. $3\left(\mathrm{~b}_{3}\right)$ and $\left.\left(\mathrm{c}_{3}\right)\right)$. The $3 \mathrm{D}$ images of the bare nanoparticles and functionalized nanoparticles are shown in Fig. $3\left(b_{2}\right)$ and $\left(c_{2}\right)$. The SPIONs crystalline nature is presented in the image provided by high resolution transmission electron microscopy (HRTEM, Fig. 3( $\left.\mathrm{a}_{1}\right)$ ). A typical structure of the core-shell (SPIONs-Br-FA) that was slightly dispersed appeared upon $\mathrm{Br}$ and FA conjugation, as shown in Fig. $3\left(\mathrm{a}_{3}\right)$, while a thick layer $(12-15 \mathrm{~nm})$ was clearly observed on the outer shell of the core. The results obtained via HRTEM are compared herein to the data obtained via fast Fourier transform (FFT), as seen in (Fig. $3\left(\mathrm{a}_{1}\right)$ and $\left(\mathrm{a}_{2}\right)$ ) and could be indexed as the (311) plane of cubic SPIONs.
Additional characterizations and physicochemical analyses of the synthesized nanoparticles through various methods, such as FT-IR, TGA, DLS, XRD, and microscopic observations in the absence of the magnetic field are reported in the ESI file (Fig. S1†).

\section{Cellular uptake of nanoparticles into 4T1 cancer cells}

In our previous published paper, ${ }^{43}$ the nanoparticles uptake into HSF 11 84, MDA-MB-231, MDA-MB-468, and HeLa cell lines was reported. In the current paper, the quantitative uptake experiments were performed by means of AAS using 4T1 cells, known to overexpress the folate receptor. ${ }^{75-79}$ After the 


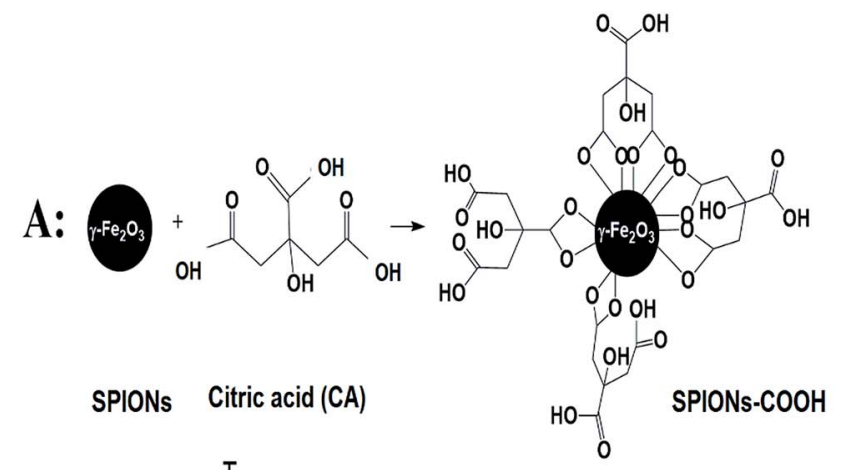

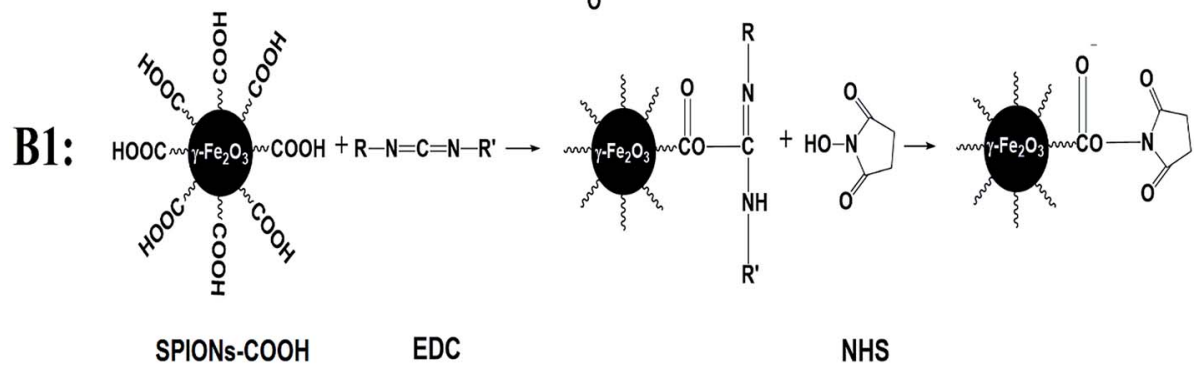

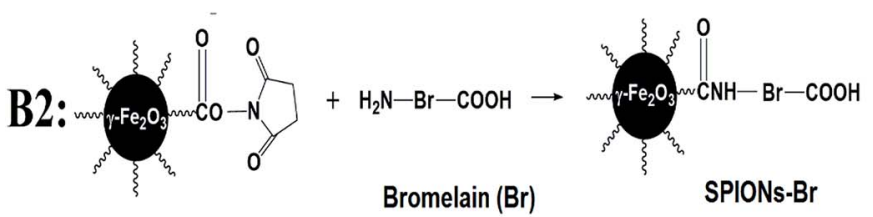

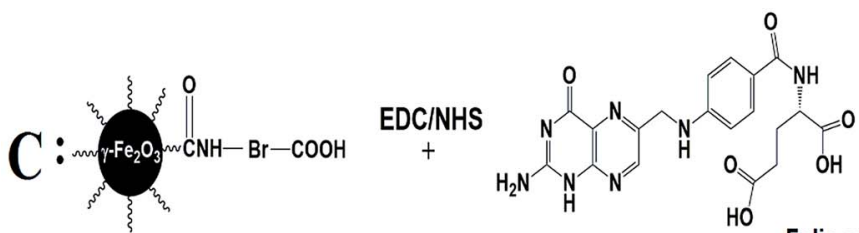

Folic acid (FA)

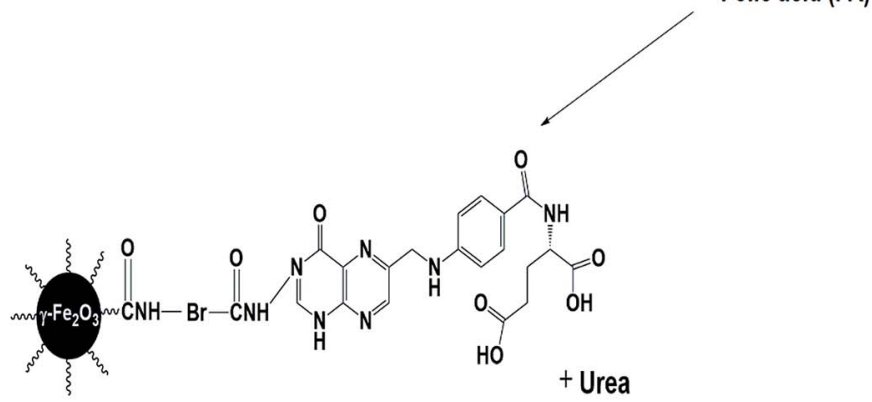

SPIONs-Br-FA

Fig. 2 Step-by-step functionalization of dual-functional SPIONs-Br-FA.

treatment of cells with suspensions of SPIONs-COOH and SPIONs-FA in three different concentrations $(100,200$, and 300 $\mu \mathrm{g} \mathrm{ml}^{-1}$ ) for 4,12 , and $24 \mathrm{~h}$, cells as mineralized cell lysates were tested to determine their iron content via measurement of their atomic absorbance at $248.3 \mathrm{~nm}$. In contrast to SPIONs-COOH, the uptake of SPIONs-FA by $4 \mathrm{~T} 1$ cells was about 2-fold higher (Fig. 4(C)). A binding assay was performed in a competitive manner for the determination of the dependency of cellular uptake on the folate receptors in FAR+ cells treated with $1 \mathrm{mM}$ of neat folic acid, which was needed to limit the folate receptordependent binding in a competitive manner. As expected, the comparative binding assay shows a sharp decreased uptake of the nanoparticles by the 4T1 cells (Fig. 4(D)). This result indicates that the uptake of SPIONs-FA was mediated by the folate receptors on the cell surface. ${ }^{43,80,81}$ On the other hand, the internalization of SPIONs-COOH and SPIONs-FA were verified using Prussian blue staining (Fig. 4(A)) and by TEM (Fig. 4(B)). Fig. 4(A) shows a higher number of nanoparticles, as the blue 

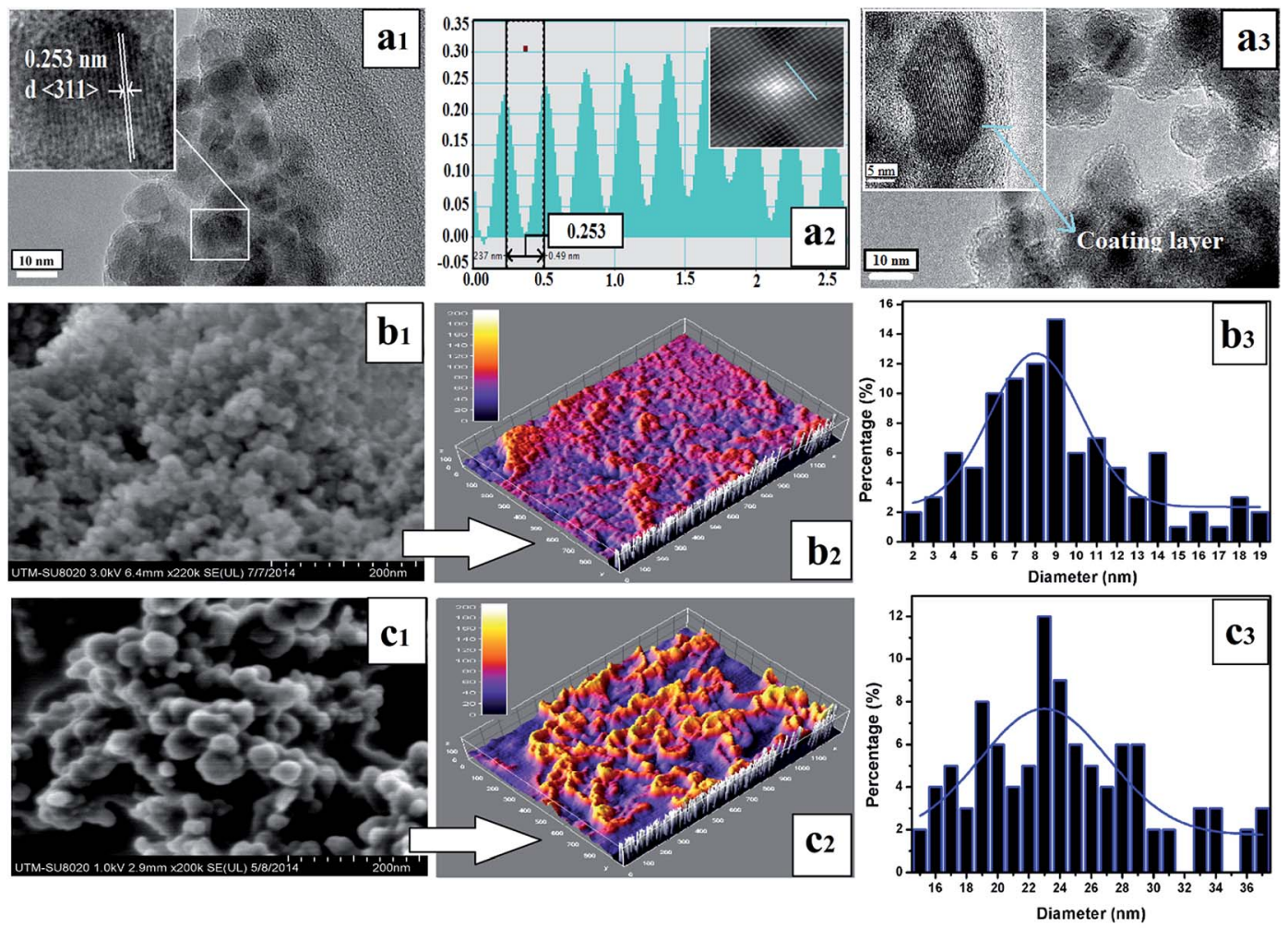

Fig. $3\left(a_{1}\right)$ TEM and HRTEM images of bare SPIONs, $\left(a_{2}\right)$ intensity histogram of SPIONs, $\left(a_{3}\right)$ TEM and HRTEM images of the functionalized nanoparticles, $\left(b_{1}\right)-\left(b_{3}\right)$ show the FESEM, 3D, and size distribution images of SPIONs, $\left(c_{1}\right)-\left(c_{3}\right)$ show the FESEM, 3D, and size distribution of the functionalized nanoparticles.

spots, within $4 \mathrm{~T} 1$ cells in a concentration-dependent manner after incubation with SPIONs-FA compared to SPIONs-COOHincubated cells. Fig. 4(B) shows SPIONs-FA internalization to a $4 \mathrm{~T} 1$ cell by electron microscopy. Although the results obtained from the TEM and Prussian blue staining confirm the results obtained from the AAS assay, in which a higher amount of SPIONs-FA are seen (blue spots) on $4 \mathrm{~T} 1$ cells when the cells were treated with SPIONs-FA, a lower number of blue spots was seen when the cells were treated with SPIONs-COOH. The results showed that SPIONs-FA was a rewarding option for targeting $4 \mathrm{~T} 1$ cancer cells.

\section{In vitro biocompatibility evaluation and cytotoxicity assay}

The biocompatibility levels of the SPIONs, SPIONs-COOH, and SPIONs-FA were qualitatively determined using the colorimetric MTT assay toward HSF 1184, MDA-MB-468, MDA-MB231, and HeLa cells as reported in our previous published paper, ${ }^{43}$ while the biocompatibility of $4 \mathrm{~T} 1$ cells were evaluated in this paper, and for a better comparison, all the data are reported in one graph in this paper. All the HSF 1184, MDA-MB231, MDA-MB-468, HeLa, and 4T1 cell lines were incubated with 100, 200, 300, 500, and $1000 \mu \mathrm{g} \mathrm{Fe} \mathrm{ml}{ }^{-1}$ of each SPIONs, SPIONs-COOH, and SPIONs-FA for $24 \mathrm{~h}$. As illustrated in Fig. 5, after $24 \mathrm{~h}$ incubation with SPIONs-COOH and SPIONs-FA, the viability of all the cell types were still $>70 \%$ at all $\mathrm{Fe}$ incubation concentrations. These results agree with the literature. ${ }^{82,83}$ The
SPIONs-COOH and SPIONs-FA showed $<30 \%$ cell inhibition, even at the highest concentration of $1000 \mu \mathrm{g} \mathrm{ml}{ }^{-1}$; however, the viability of the cells treated with SPIONs was lower in all cases, showing that while SPIONs are slightly toxic to the cells, SPIONs-COOH and SPIONs-FA are reliably biocompatible. In vitro blood compatibility test were carried out and the results are reported in the ESI file (Fig. S2 $\dagger$ ), which indicated that the synthesized delivery system was perfectly tolerable to blood.

In the case of the cells incubated with SPIONs- $\operatorname{Br}(100,200$, 300, 500, and $1000 \mu \mathrm{g} \mathrm{Fe} \mathrm{ml}{ }^{-1}$ ), SPIONs-Br-FA (100, 200, 300, 500 , and $1000 \mu \mathrm{g} \mathrm{Fe} \mathrm{ml}^{-1}$ ) and neat $\mathrm{Br}$ (note: the concentration of neat $\mathrm{Br}$ in each group was equal to the concentration of $\mathrm{Br}$ in the corresponding SPIONs-Br and SPIONs-Br-FA groups), the $24 \mathrm{~h}$ cell viabilities are also shown in Fig. 5.

The in vitro cytotoxicity profiling of SPIONs-Br, SPIONs-Br$\mathrm{FA}$, and neat $\mathrm{Br}$ in the HSF 1184 and MDA-MB-231, MDA-MB468, HeLa, and 4T1 cells are also shown in Fig. 5. The SPIONs-Br-FA exhibited a boosted cytotoxicity in FAR+ cancer cells in comparison with cells treated with SPIONs-Br and neat $\mathrm{Br}$ at the same concentrations of bromelain. The $\mathrm{IC}_{50}$ value is defined as the concentration inhibiting $50 \%$ of cell growth, with a $95 \%$ confidence interval $(95 \% \mathrm{CI})$ typically stated at the $95 \%$ of confidence level, which measures the probability that a population parameter will fall between two set values. $\mathrm{IC}_{50}$ values of SPIONs in different formulations, neat $\mathrm{Br}$, and cisplatin are illustrated in Table 3. As shown in Table 3 , the $\mathrm{IC}_{50}$ values and $95 \%$ CI (confidence intervals) of bare SPIONs increased after 
A
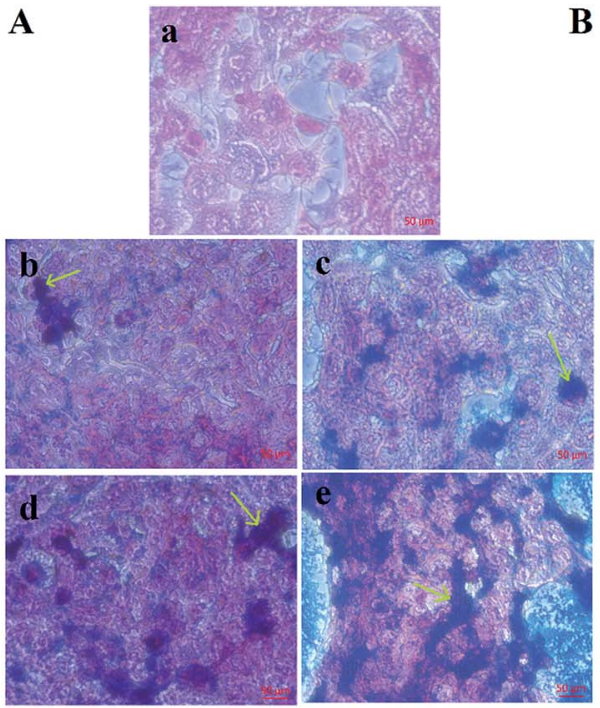

C

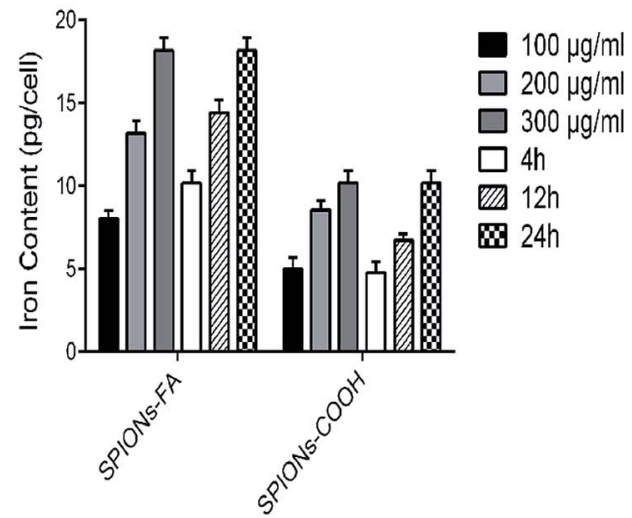

B

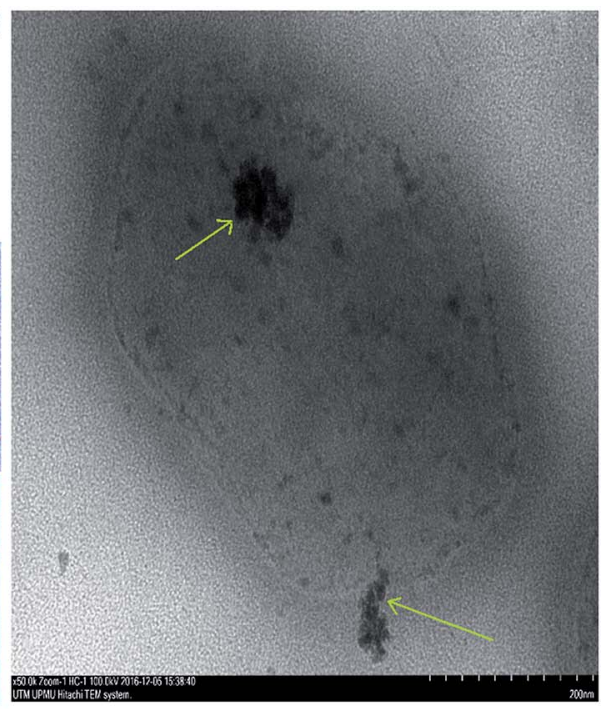

D

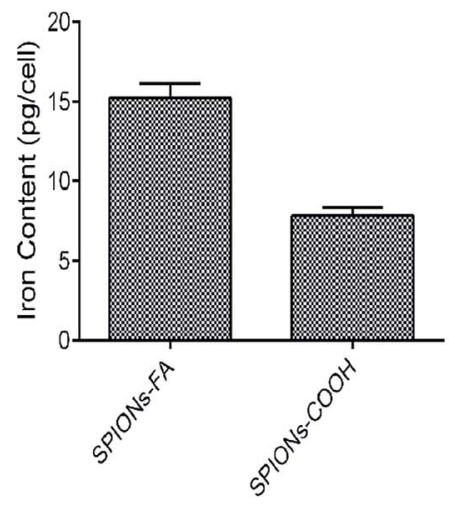

Fig. 4 (A) Prussian blue assay ((a) no treatment, (b) SPIONs-COOH $100 \mu \mathrm{g} \mathrm{ml}^{-1}$, (c) SPIONs-COOH $200 \mu \mathrm{gl}^{-1}$, (d) SPIONs-FA $100 \mu \mathrm{g} \mathrm{ml}{ }^{-1}$, (e) SPIONs-FA $200 \mu \mathrm{g} \mathrm{ml}^{-1}$ ). (B) TEM image. (C) AAS assay. (D) Competitive binding assay.

citrate coating and remained high even after folate conjugation, which shows the low cytotoxicity and compatibility of SPIONsFA as a delivery vehicle in contact with the cells.

On the other hand, the calculated IC $_{50}$ values for SPIONs-Br were lower for all cells compared to the neat $\mathrm{Br}$. The lower cell viability (reduced $\mathrm{IC}_{50}$ ) was assigned to the fact that SPIONs-Br were efficiently endocytotically taken up in comparison with the molecules of neat $\mathrm{Br}$, which passively find their way through the membrane via diffusion. ${ }^{84}$ These results are in agreement with the results reported by Danhier et al. ${ }^{85}$ where it was illustrated that via the conjugation of doxorubicin (an anthracycline antibiotic commonly used in cancer chemotherapy) to nanoparticles, the toxicity was highly increased. The results of this study suggested that doxorubicin-conjugated nanoparticles could efficiently decrease the effective dose received by patients over the course of the therapy. Similarly, the toxicity of oxaliplatin-conjugated nanoparticles was investigated. ${ }^{86}$ Oxaliplatin is known as a cisplatin analog, which has been utilized for the treatment of colorectal cancer. However it effectively works, oxaliplatin does not offer any targeting properties to track and bind to cancer cells, so it attacks any kind of healthy cells, which uncontrollably divide. To improve this method of chemotherapy, drug delivery must be enhanced. Brown et al. showed that the capabilities of oxaliplatin increased when it was conjugated to nanoparticles. They reported that the in vitro cytotoxicity after conjugation was increased by a factor of 5 -fold, which was again assigned to the fact that conjugated particles could pass the membrane of cancer cells via endocytosis. ${ }^{86}$

However, in the current study, the $\mathrm{IC}_{50}$ values were significantly lower for FAR+ cancer cells when treated with SPIONsBr-FA compared to when treated with SPIONs-Br and neat $\mathrm{Br}$, while there was no significant difference for FAR- cells. It is evident from the results that the SPIONs-Br-FA was able to induce significantly more cell death at low doses (in bold in Table 3) as compared to neat $\mathrm{Br}$ and SPIONs-Br (Fig. 5), especially for FAR+ cancer cell lines (HeLa, MDA-MB-231, 4T1). The higher efficiency of $\mathrm{Br}$ transport via nanoparticles through the mechanism of the receptor-mediated endocytosis pathway into FAR+ cancer cells (HeLa, MDA-MB-231, 4T1) in comparison with the mechanism of the passive diffusion of neat Br into the FAR- 


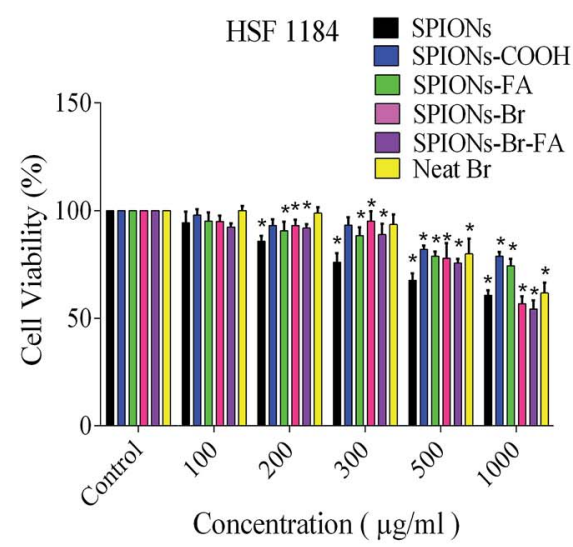

(a)

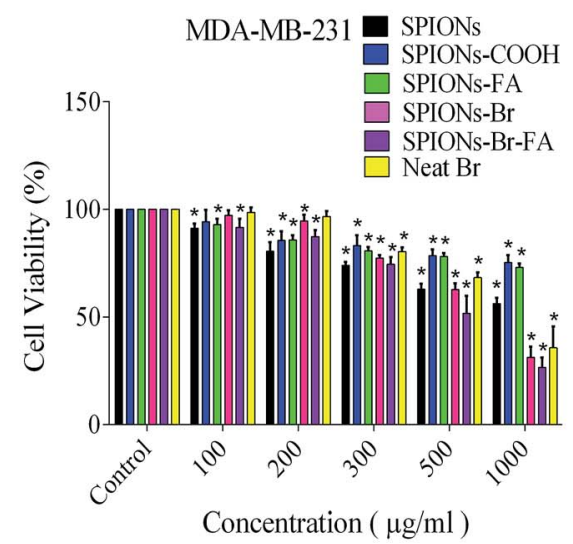

(c)

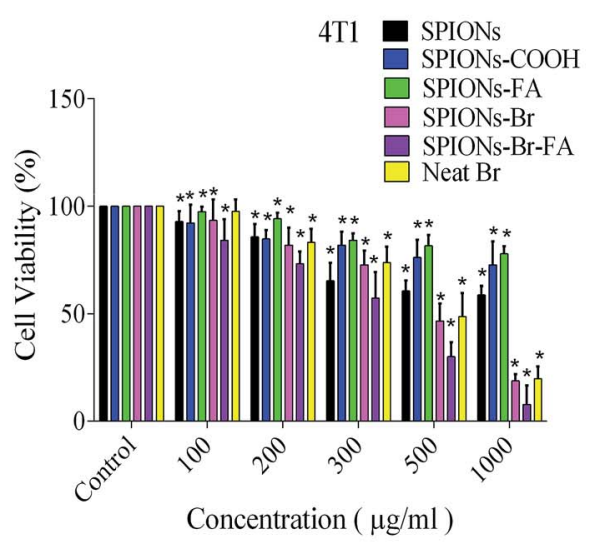

(e)

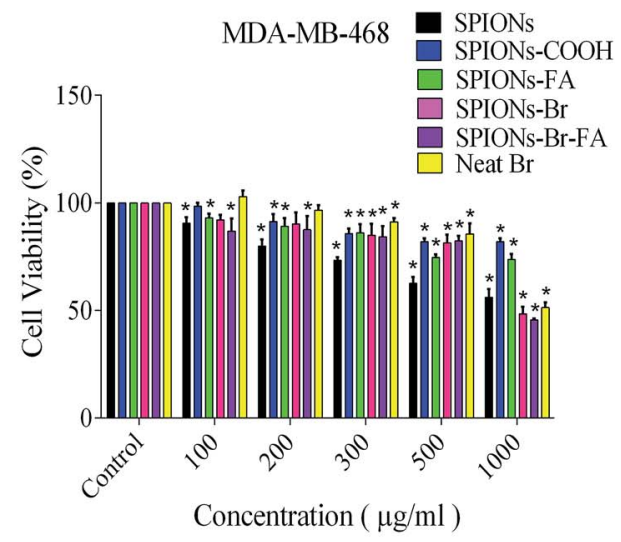

(b)

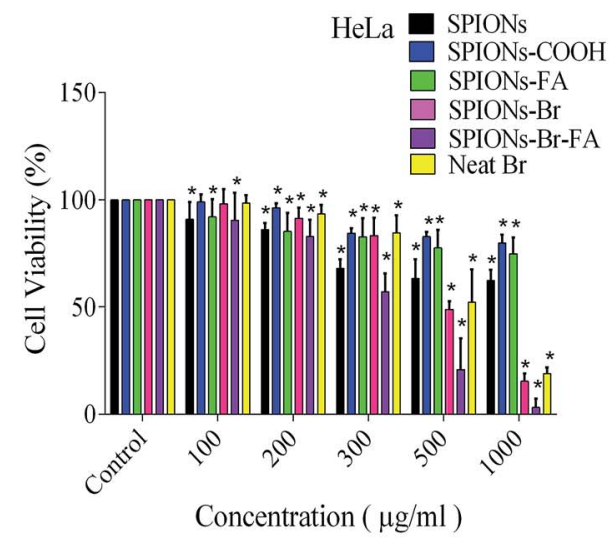

(d)

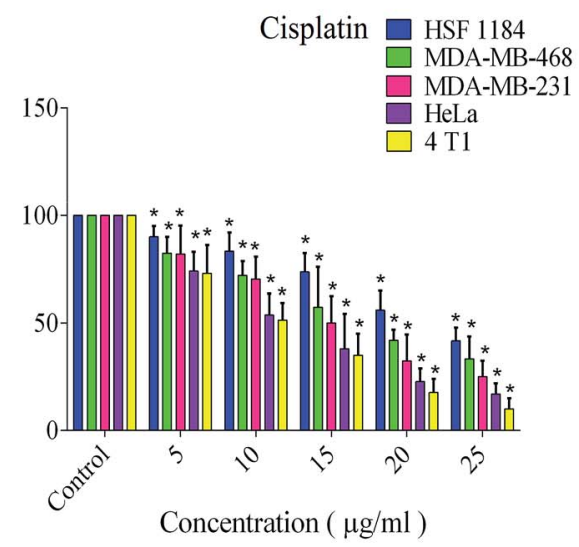

(f)

Fig. 5 MTT assay. Each value is the mean \pm S.E.M. of six replicates out of three independent experiments. (*) indicates a significant difference compared to the control analyzed by the unpaired $t$-test, followed by the Holm-Sidak post hoc test $(p<0.05)$.

cancer cells (HSF 1184, MDA-MB-468) may be the reason why SPIONs-Br-FA exhibited increased cytotoxicity in FAR+ cancer cell lines. ${ }^{87,88}$

To conclude, the $\mathrm{IC}_{50}$ value of neat $\mathrm{Br}$ had significant difference for the FAR+ cancer cells when compared with SPIONs-Br-FA, while there were no significant difference for the FAR - cell lines. Also, there was no significant difference between the $\mathrm{IC}_{50}$ value of neat $\mathrm{Br}$ and SPIONs-Br. Therefore, for further morphological analysis, apoptotic detection, scratch motility, and the clonogenic inhibition assays, neat $\mathrm{Br}$ and SPIONs-Br-FA-treated cells were compared to each other.

\section{Morphological assessment and apoptosis detection}

The morphologies of HSF 1184, MDA-MB-468, HeLa, MDA-MB231 , and $4 \mathrm{~T} 1$ cells after treatment with neat $\mathrm{Br}$ (at the $\mathrm{IC}_{50}$ concentration), SPIONs-Br-FA (at the $\mathrm{IC}_{50}$ concentration of neat 
Table 3 Inhibitory effect ( $\mathrm{C}_{50}$ values) of SPIONs in different formulations, neat $\mathrm{Br}$, and cisplatin against cells after $24 \mathrm{~h}$. The IC $\mathrm{C}_{50}$ values were calculated by GraphPad Prism using nonlinear regression analysis

\begin{tabular}{|c|c|c|c|c|c|}
\hline \multirow{2}{*}{ 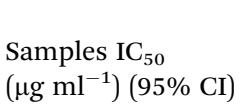 } & \multicolumn{2}{|l|}{ FAR - } & \multicolumn{3}{|l|}{ FAR+ } \\
\hline & HSF 1184 & MDA-MB-468 & MDA-MB-231 & HeLa & $4 \mathrm{~T} 1$ \\
\hline SPIONs & $1455(1047$ to 2021$)$ & 1188 (941.8 to 1499$)$ & $1170(929.3$ to 1473$)$ & $1235(740.7$ to 2058$)$ & 1144 (719.6 to 1819$)$ \\
\hline SPIONs-COOH & $14086(5425$ to 36574$)$ & $9273(2294$ to 37487$)$ & $7355(2918$ to 18540$)$ & $7398(2662$ to 20557$)$ & $5088(5425$ to 36574$)$ \\
\hline SPIONs-FA & $4853(3071$ to 8272$)$ & $5185(2402$ to 11194$)$ & $5282(2777$ to 10050$)$ & $5039(1912$ to 13282$)$ & $4726(3071$ to 8272$)$ \\
\hline Neat $\mathrm{Br}$ & 240.7 (199.3 to 290.8$)$ & $193.1(177.9$ to 209.6$)$ & $136.7(123.1$ to 151.7$)$ & $100.9(95.58$ to 106.5$)$ & $91.55(85.15$ to 98.44$)$ \\
\hline SPIONs-Br & $217.9(182.8$ to 259.7$)$ & $195.5(160.7$ to 230.5$)$ & $121.6(112.9$ to 131.1$)$ & $94.85(91.03$ to 98.84$)$ & $88.15(83.46$ to 93.10$)$ \\
\hline SPIONs-Br-FA & $213.3(184.6$ to 246.3$)$ & $189.4(144.6$ to 248.1$)$ & $101.2(92.25$ to 111$)$ & $\mathbf{6 0 . 9 8}(57.32$ to 64.88$)$ & $\mathbf{6 1 . 1 8}(56.48$ to 66.26$)$ \\
\hline Cisplatin & $22.34(20.75$ to 24.05$)$ & $16.86(15.52$ to 18.32$)$ & $14.34(13.23$ to 15.54$)$ & $10.32(9.526$ to 11.18$)$ & $9.602(8.777$ to 10.50$)$ \\
\hline
\end{tabular}

$\mathrm{Br}$ ), and cisplatin (as a positive control, at the cisplatin $\mathrm{IC}_{50}$ concentration) were studied under an inverted microscope are shown in Fig. 6. A perfect way to depict and define apoptosis on the basis of morphological alterations after treatment is using phase-contrast microscopy. ${ }^{89}$ In a previous study by Gani et al.,${ }^{65}$ the morphological alternations of colon and ovarian cancer cells after Br treatment indicated a bromelain apoptotic effect on cancer cells. In the current study, the morphological alternations of HSF 1184, MDA-MB-468, HeLa, MDA-MB-231, and 4T1 cell lines after neat $\mathrm{Br}$ and SPIONs-Br-FA treatment were observed and compared. Apparent changes in morphology were observed in the treated cells, namely regarding membrane
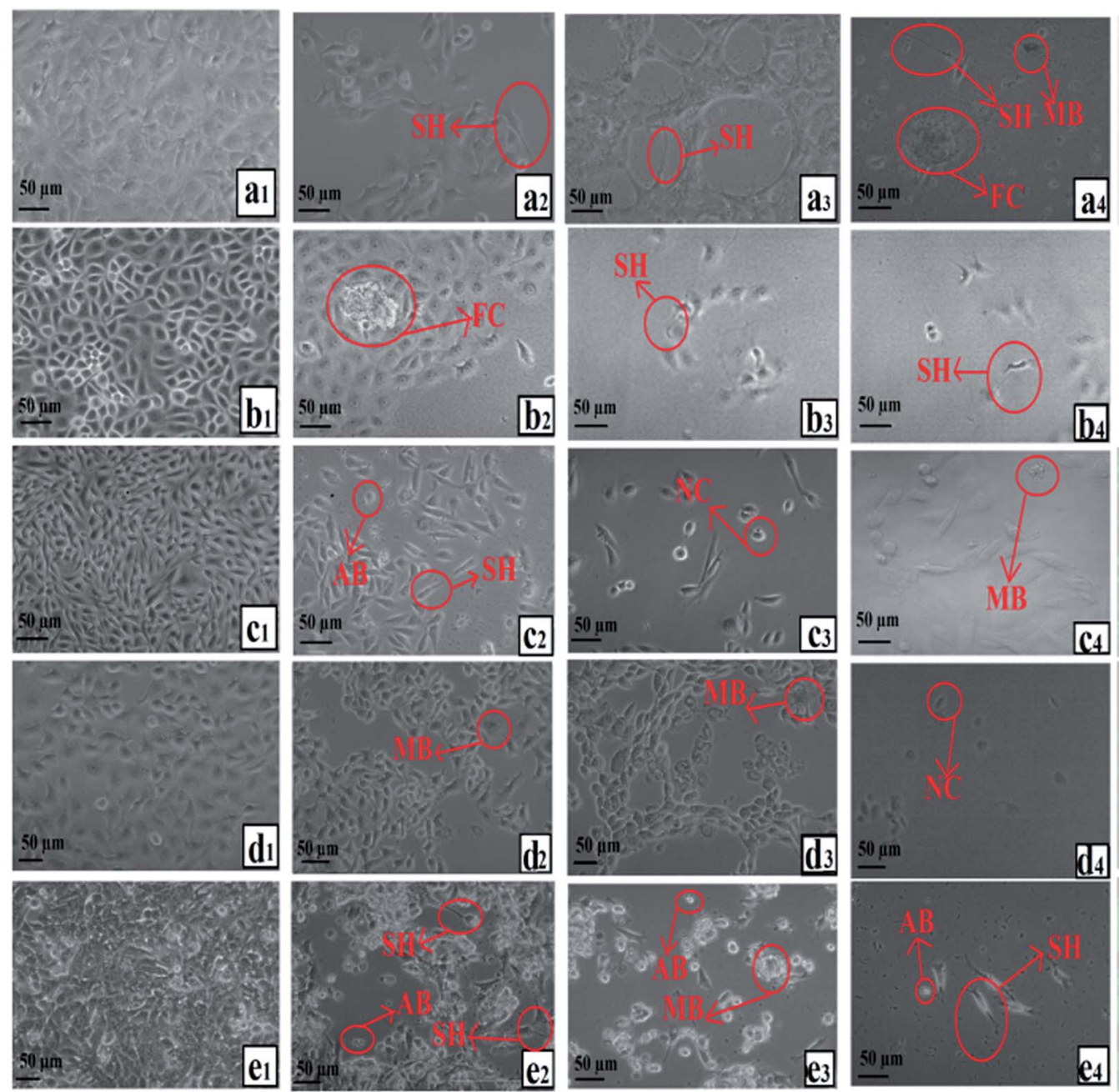

Fig. 6 Growth inhibitory effect under an inverted microscope, (a) HSF 1184, (b) MDA-MB-231, (c) HeLa, (d) MDA-MB-468, (e) 4T1 ((1) no treatment, (2) neat $\mathrm{Br}$, (3) SPIONs-Br-FA, (4) cisplatin). 
blebbing (MB), apoptotic bodies (AB), nuclear compaction (NC), rounded up and floating cells (FC), and cell shrinkage ( $\mathrm{SH}$ ). These morphological changes were previously reported in apoptotic cells. ${ }^{89-91}$ Among the morphological changes and dead cell characteristics, rounding and cell detachment were more remarkable in FAR+ cancer cells when treated with SPIONs-BrFA compared with neat Br-treated cells. As a result, SPIONs-BrFA induced significant apoptosis compared to neat $\mathrm{Br}$ in FAR+ cancer cell lines, which corroborates with the MTT results in this study.

One key consideration in developing drugs is the apoptosis induction. Most of the anticancer agents currently in use are capable of inducing apoptosis in susceptible cells. ${ }^{\mathbf{9 2 , 9 3}}$ Apoptosis: a significant model of cell death, which is an active process to destroy the cell, that takes place in response to different agents, such as ionizing radiation or anticancer agents. ${ }^{94}$ As a vital dye, Acridine orange (AO) is taken up by both non-viable and viable cells. The resulting nuclei can be observed in green under a fluorescence microscope, while the cells stained with ethidium bromide (EB, only non-viable cells) lose the integrity of their cytoplasmic membrane and their nuclei turns red. Based on chromatin condensation, fluorescence emission, and morphological changes, identification of the different types of cells was carried out, where viable cells showed a normal morphology with uniform green nuclei. Highly condensed cells, which formed yellow green fragments, were identified as early apoptotic cells, whereas orange-red fragmented/condensed nuclei and orange-red chromatin in round nuclei were a highlighted morphological characteristic of late apoptotic and necrotic cells, respectively. ${ }^{64}$ For $24 \mathrm{~h}$, the cells (HSF 1184 and MDA-MB-231, MDA-MB-468, HeLa, and 4T1) were exposed to neat $\mathrm{Br}$ (at the $\mathrm{IC}_{50}$ concentration), SPIONs-Br-FA (at the $\mathrm{IC}_{50}$ concentration of neat $\mathrm{Br}$ ), and cisplatin (as a positive control, at the $\mathrm{IC}_{50}$ concentration of cisplatin), and then stained with EB and AO. Neat Br-, SPIONsBr-FA-, and cisplatin-treated cells exhibited transformed morphological characteristics of non-viable cells under AO/EB staining, while green and viable cells with round and nonaffected nuclei were snapped in the negative control groups. Fig. 7 shows that there were no distinct morphological changes in the control (i.e., no treatment) groups, but cells exhibited the induction of apoptosis after neat $\mathrm{Br}$ and SPIONs-Br-FA
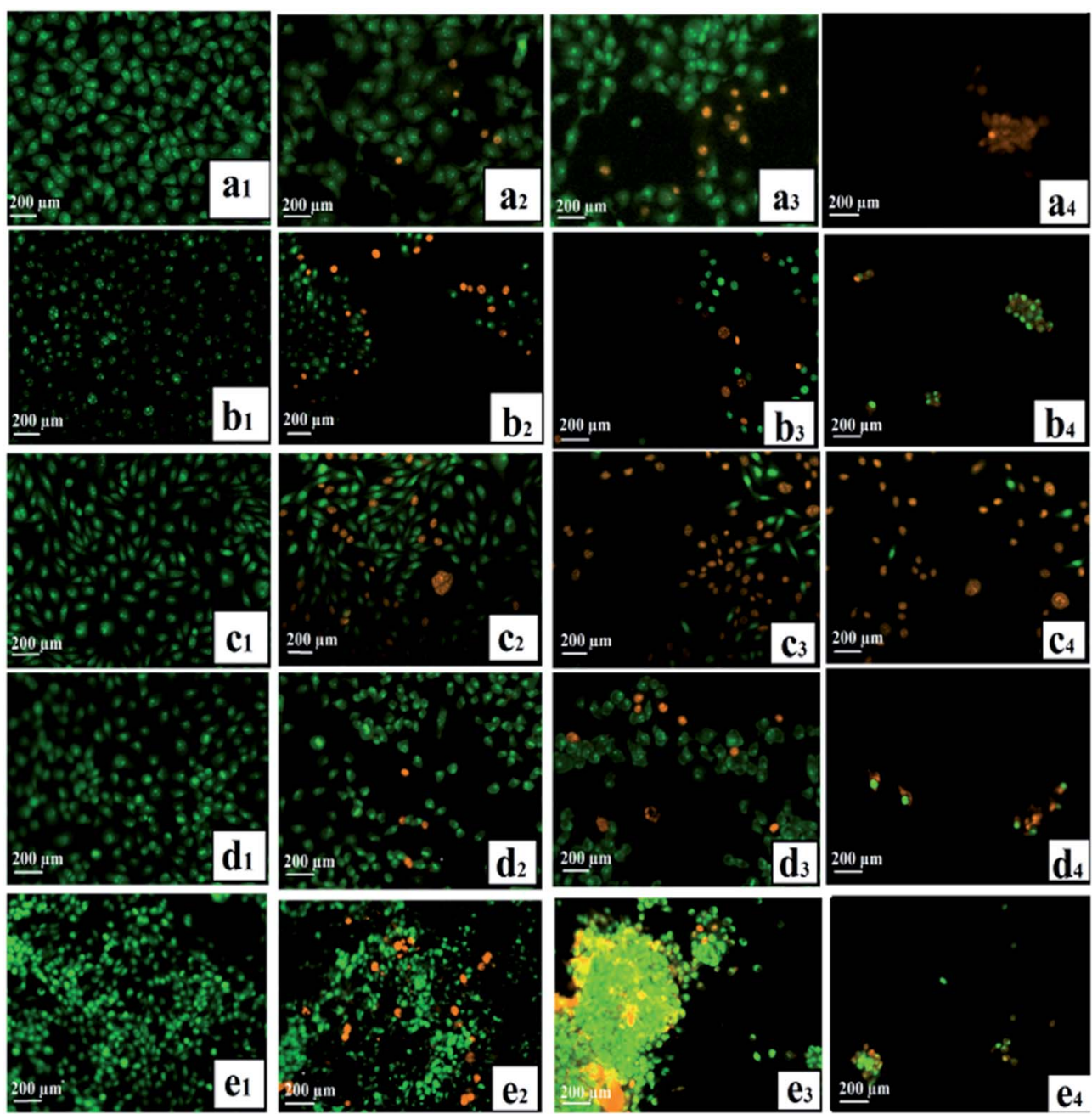

Fig. 7 Detection of apoptosis by AO/EB staining, (a) HSF 1184, (b) MDA-MB-231, (c) HeLa, (d) MDA-MB-468, (e) 4T1 ((1) no treatment, (2) neat Br, (3) SPIONs-Br-FA, (4) cisplatin). 
treatments. These results illustrate that SPIONs-Br-FA can bring about enormous detachment, along with leading to cluster and aggregate formation of the FAR+ cancer cells compared with neat Br-treated cells. The frequency of necrotic cells with uniformly stained orange nuclei and the percentage of apoptotic cells was sharply increased when FAR+ cancer cells were treated with SPIONs-Br-FA (Fig. S3†).

Overall, the SPIONs-Br-FA was shown to be more effective at inducing apoptosis, suppressing the cell growth, and introducing morphological changes in FAR+ cancer cells compared to neat Br-treated cells. The reason for this could be the higher internalization of $\mathrm{Br}$ through the FAR receptors on the surface of FAR+ cancer cells, which causes $\mathrm{Br}$ to be more internalized in the FAR+ cells and establishes a higher cytotoxicity and consequently, changes in the FAR+ cancer cells. These results are in agreement with the MTT and inverted microscope results.

\section{Scratch motility and clonogenic inhibition assays}

The cell migration assay was performed on confluent monolayers of FAR+ cancer cell lines. Non-treated cells were used as a negative control. Scratching of the cells was performed, as explained in the methodology, prior to them being cultured using fresh medium in the absence or in the presence of neat $\mathrm{Br}$ (at the $\mathrm{IC}_{50}$ concentration) and SPIONs-Br-FA (at the $\mathrm{IC}_{50}$ concentration of neat $\mathrm{Br}$ ). The data are shown in Fig. 8(a)-(c) for the HeLa, MDA-MB-231, and 4T1 cell lines, respectively, which clearly showed that the control cells gained a full confluency after $24 \mathrm{~h}$, whereas cells treated with neat $\mathrm{Br}$ and SPIONs-Br-FA showed the ability to migrate to a minimum with a complete stop in migration $24 \mathrm{~h}$ subsequent to the incubation. The obtained results illustrated that the migration of FAR+ cells was effectively reduced in a time-dependent manner once they were incubated with SPIONs-Br-FA. As a result, the SPIONs-Br-FA displayed higher migration inhibition rates compared to neat $\mathrm{Br}$ in FAR+ cancer cells. The scratch assay findings suggest that SPIONs-Br-FA have the ability to inhibit significantly the migration of HeLa, MDA-MB-231, and 4T1 cell lines.

The spread of metastatic cancer cells is the reason behind almost $90 \%$ of the cancer deaths in human and is a significant barrier in cancer therapy. ${ }^{95,96}$ Cell migration is one of the most crucial steps involved in metastasis, which is the most lifethreatening stage of cancer. ${ }^{97}$ As shown in Fig. 8(a)-(c), the neat $\mathrm{Br}$ and SPIONs-Br-FA inhibited significantly the migration of MDA-MB-231, HeLa, and 4T1 cell lines. Cell migration quantitative analysis results are shown in Fig. S4, $\dagger$ with the results expressed as a percentage of cell migration after $24 \mathrm{~h}$. As a result, cells treated with SPIONs-Br-FA showed better inhibition of cell migration compared to neat $\mathrm{Br}$ in $\mathrm{FAR}+$ cancer cells. It can be suggested that the higher inhibitory effects of SPIONs-Br-FA on MDA-MB-231, HeLa, and 4T1 cells migration
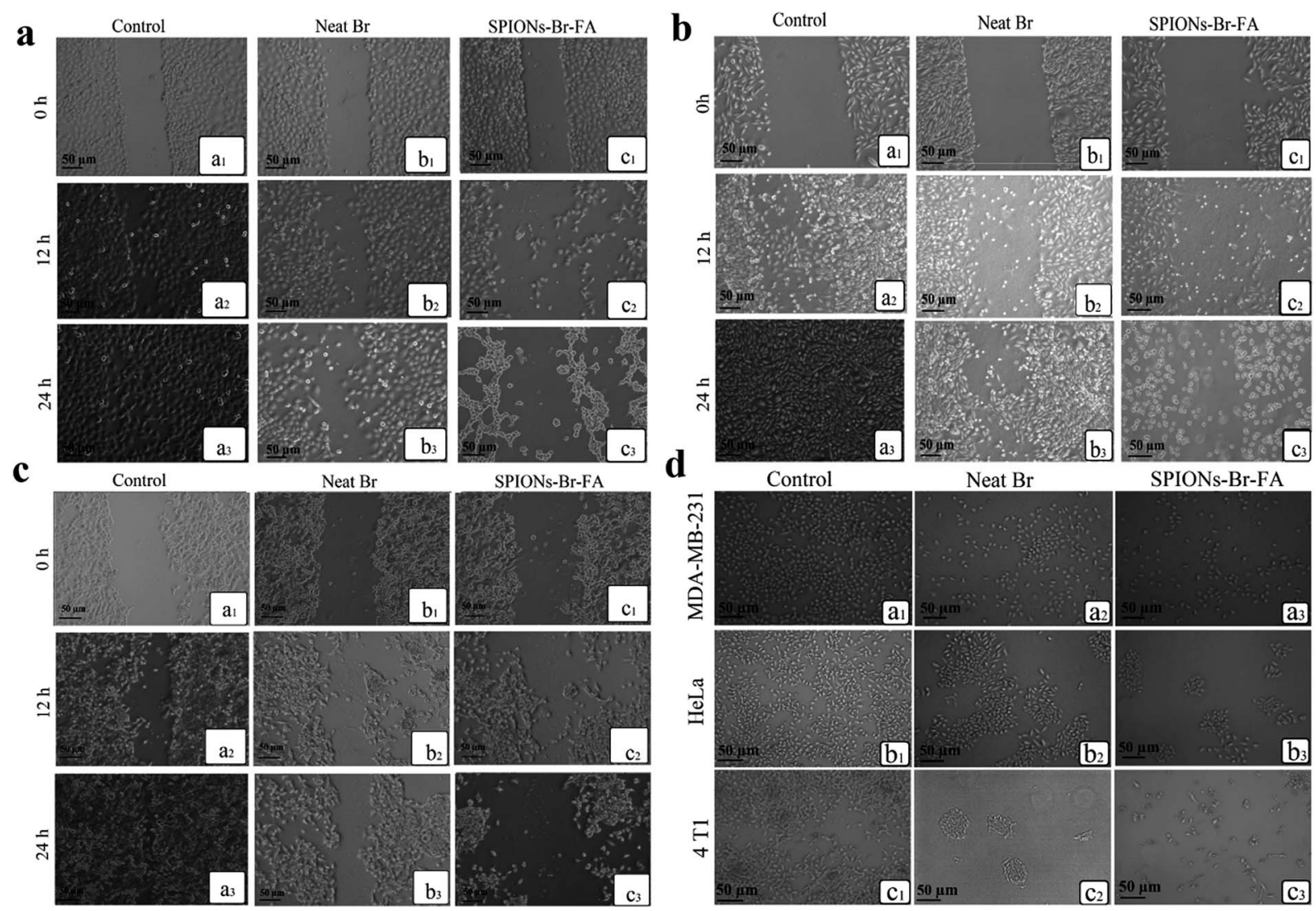

Fig. 8 Inhibition of (a) MDA-MB-231, (b) HeLa, and (c) 4T1 cell lines migration after treatment with neat $\mathrm{Br}$ and SPIONs-Br-FA. Images were snapped with an inverted phase-contrast microscope $(50 \times)$ at different time intervals $(0,12$, and 24 h). (d) Qualitative analysis of the colonyforming-inhibition potential of neat $\mathrm{Br}$ and SPIONs-Br-FA on FAR+ cancer cells. 
were likely because of its higher cytotoxic effect compared to the neat $\mathrm{Br}$, which was due to the greater internalization of $\mathrm{Br}$ through the FAR receptors on the surface of FAR+ cancer cells. As a result, more Br was internalized to the FAR+ cells, which led to a higher cytotoxicity and consequently a higher number of cells lost their migration ability and the migration percentage of FAR+ cancer cells was significantly decreased. It could thus be concluded that SPIONs-Br-FA effectively inhibited FAR+ cancer cells migration compared to the neat $\mathrm{Br}$.

In order to compare the potential of neat $\mathrm{Br}$ and SPIONs-BrFA for suppressing the growth of FAR+ cell lines, a clonogenic assay was carried out. For the measurement of clonogenicity, the cells were exposed to neat $\mathrm{Br}$ (at the $\mathrm{IC}_{50}$ concentration) and SPIONs-Br-FA (at the $\mathrm{IC}_{50}$ concentration of neat $\mathrm{Br}$ ). As depicted in Fig. 8(d), the findings revealed a significant clonogenic inhibition of all FAR+ cancer cells treated with neat $\mathrm{Br}$ and SPIONs-Br-FA. Non-treated cells (negative control) produced a large number of colonies compared to treated cells. The size and number of colonies were significantly reduced, particularly for SPIONs-Br-FA treated FAR+ cancer cells. Comparisons between the colony-forming abilities of neat $\mathrm{Br}$ and SPIONs- $\mathrm{Br}-$ FA in FAR+ cancer cells indicated that the SPIONs-Br-FA had a higher colony-forming-inhibitory effect compared to neat $\mathrm{Br}$. It was clearly evident that SPIONs-Br-FA exerted a suppressing effect on the colony formation of FAR+ cancer cells. The reason for this could be due to the higher internalization of $\mathrm{Br}$ through the FAR receptors on the surface of FAR+ cancer cells, which led to a greater internalization of $\mathrm{Br}$ to the FAR+ cells and established a higher cytotoxicity and consequently decreased the survival rate (lower colony-forming ability). It could thus be concluded that SPIONs-Br-FA effectively decreased the colonyforming ability of FAR+ cancer cells compared to the neat $\mathrm{Br}$.

Quantitative analysis (Fig. S5 $\dagger$ ) of the colony-forminginhibition potential of both neat $\mathrm{Br}$ and SPIONs-Br-FA against MDA-MB-231, HeLa, and 4T1 cells indicated that the latter displayed the best ability. Pair-wise comparison of the SPIONs-Br-FA versus neat $\mathrm{Br}$ indicated that Br's effectiveness was lower at limiting the growth, migration, and colonyforming abilities of FAR+ cell lines.

\section{In vivo anticancer efficacy}

The 4T1-tumor-bearing mice model was established about 2 to 2 weeks after the cancer cells induction to the female Balb/C mice. Fig. 9(e) shows the 4T1 breast tumor in situ, which was confirmed by histological analysis. The tumor region consisted of viable tumor cells, which displayed numerous focal areas of necrosis, suggesting a massive tumor formation.

The most common animal models used in biomedical research are mice due to $95 \%$ of their genes sharing homology with humans. Observations in this study showed that tumors began to appear within 2 to 3 weeks after the initiation of 4T1 cells. $24 \mathrm{~h}$ after $4 \mathrm{~T} 1$ cells inoculation, the mice were subjected to the first treatment (intravenous injection (IV)). The groups ( $n=$ 6) were as follows: saline, SPIONs-COOH $\left(10 \mathrm{mg} \mathrm{kg}^{-1}\right)$, neat $\mathrm{Br}$
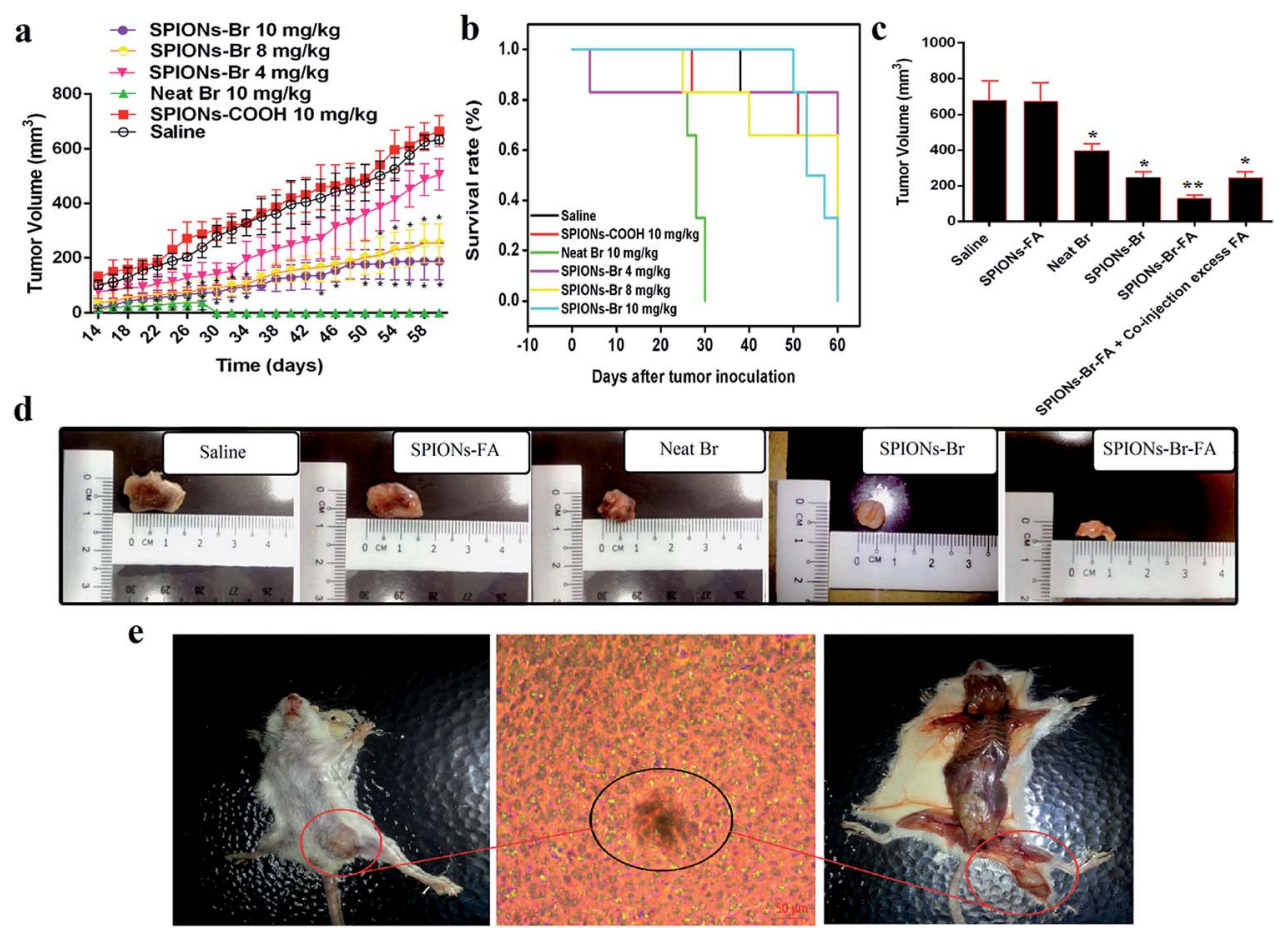

Fig. 9 (a) Tumor volume after treatment (group 1), (*) indicates significant difference compared to the control analyzed by unpaired $t$-test followed by the Holm-Sidak post hoc test $(p<0.05)$. (b) Survival rate\% after treatment (group 1). (c) Tumor volume after treatment (group 2$)$, $(* P<$ $0.05)$ and $(* * P<0.01)$ indicate significant differences compared to the control analyzed by one-way ANOVA. (d) Extracted tumors after treatment (group 2). (e) Image of mice bearing the 4T1 breast tumor in situ and a histological slice of tumor. The tumor section was stained using H\&E staining and observed under a microscope $(100 \times)$. 
(10 mg kg $\left.{ }^{-1}\right)$, SPIONs-Br (10 mg kg $\left.{ }^{-1}\right)$, SPIONs-Br $\left(8 \mathrm{mg} \mathrm{kg}^{-1}\right)$, and SPIONs-Br $\left(4 \mathrm{mg} \mathrm{kg}^{-1}\right)$. As shown in Fig. 9(a), the tumor growth rate of the saline- and SPIONs-COOH-injected groups was significantly higher than the other groups treated with neat $\mathrm{Br}$ and SPIONs-Br at different concentrations, and the survival period of the 4T1-tumor-bearing mice model, which was observed for 60 days after tumor implantation showed that SPIONs-Br (at a concentration of $8 \mathrm{mg} \mathrm{kg}^{-1}$ ) prolonged the lifespan of the mouse model (Fig. 9(b)) compared to SPIONs-Br (at a concentration of $10 \mathrm{mg} \mathrm{kg}{ }^{-1}$ ) and neat $\mathrm{Br}$ (at a concentration of $10 \mathrm{mg} \mathrm{kg}{ }^{-1}$ ). These results demonstrated that the treatment of the 4T1-bearing mice model with SPIONs-Br $(8 \mathrm{mg}$ $\mathrm{kg}^{-1}$ ) significantly inhibited tumor growth and improved the survival rate. Therefore, the concentration of $8 \mathrm{mg} \mathrm{kg}^{-1}$ was chosen to be used for the experiments in the second group.

The second group of experiments was designed to find out the tumor inhibition effect at this concentration for different nanoparticles formulation and to explore the FA targeting function in a living model. The second groups $(n=6)$ of experiments were injected intravenously by saline, SPIONs-FA $\left(8 \mathrm{mg} \mathrm{kg}^{-1}\right)$, neat $\mathrm{Br}\left(1 \mathrm{mg} \mathrm{kg}{ }^{-1}\right)$, SPIONs-Br $\left(8 \mathrm{mg} \mathrm{kg}^{-1}-1 \mathrm{mg}\right.$ $\mathrm{kg}^{-1} \mathrm{Br}$ concentration), SPIONs-Br-FA (8 mg kg${ }^{-1}-1 \mathrm{mg} \mathrm{kg}^{-1} \mathrm{Br}$ concentration), and SPIONs-Br-FA ( $8 \mathrm{mg} \mathrm{kg}^{-1}-1 \mathrm{mg} \mathrm{kg}^{-1} \mathrm{Br}$ concentration) + the coinjection of excess FA (1 mM free folic acid). The amounts of $\mathrm{Br}$ administered were $1 \mathrm{mg} \mathrm{kg}^{-1}$ in all of the formulations.

As shown in Fig. 9(c), the tumor volume measurements 60 days after treatment for the second group with different formulations (at a concentration of $8 \mathrm{mg} \mathrm{kg}^{-1}$ ) demonstrated that the mice treated with SPIONs-Br-FA had an appreciably smaller tumor than the other treatment groups. To be more specific, the live models were sacrificed and the tumors were then extracted and subjected to size measurement.

The photographs of the tumors illustrated that the smallest tumor belonged to the live models injected with SPIONs-Br-FA, followed by the live models injected with SPIONs-Br and neat $\mathrm{Br}$ (Fig. 9(d)). During the period of this experiment (60 days), all of the live models were alive. The tumor volumes of each group changed differently, owing to the targeting effect of SPIONs-BrFA to the tumor site, whereby more Br reached the tumor site, which led to better results. The ability of the higher targeting efficiency to the tumor by SPIONs-Br-FA was striking and directly responsible for the higher tumor suppression efficacy than for the other formulations in the treatment groups.

These results are in agreement with the study carried out by ref. 66, which demonstrated that the targeted delivery of methotrexate (anticancer agent) increased its anti-tumor activity and markedly decreased its toxicity which is not possible with a neat and non-targeting methotrexate. In 2014, ${ }^{98}$ a study showed that bromelain's anticancer activity could be significantly boosted and the lifespan of bromelain-treated tumor-bearing mice could be remarkably extended when bromelain was encapsulated into poly(lactic-co-glycolic acid) in comparison to neat bromelain. It is satisfactory to draw a conclusion in this study that SPIONs-Br-FA successfully targets and finds its way into the tumor cells through FAR+ receptors, which thus affords a promising treatment, while toxic side effects remarkably declined.

\section{Biodistribution study}

To understand the biodistribution and in vivo targeting efficacy of the functionalized nanoparticles, the biodistribution of SPIONs$\mathrm{COOH}$ and SPIONs-FA in different major organs as well as in tumors, the 4T1-bearing mice model were sacrificed at 4, 12, and $24 \mathrm{~h}$ after intravenous administration. The biodistribution was expressed as the percentage of injected dose per gram of each organ (\% ID per g). The animals were sacrificed and dissected 4, 12 , and $24 \mathrm{~h}$ after injection. The live models in the control group were injected with PBS. Noteworthy quantitative and qualitative differences in the samples biodistribution was seen, s can be seen in Fig. 10 and S6, $\uparrow$ respectively. Both SPIONs-COOH and SPIONsFA taken up by the liver and spleen (parts of the reticuloendothelial system (RES)) may reduce the unpredictable side effects for effective long-term treatment. ${ }^{99}$ However, the accumulation of SPIONs-FA in the liver was higher than SPIONs-COOH, which may be due to the increment in the size and different surface characteristics of the SPIONs-FA.

These results revealed the specific localization of SPIONs-FA at the site of the tumor. Importantly, SPIONs-FA could increase the iron concentration in the tumor compared to SPIONs$\mathrm{COOH}(P<0.05)$. The iron concentration increase at the tumor site was by a factor of 1.9-fold at $4 \mathrm{~h}$ after injection, 2.1-fold at $12 \mathrm{~h}$ after injection, and 2.6-fold higher at $24 \mathrm{~h}$ after injection, as shown in Fig. 10. An increment in the blood iron concentration was seen $4 \mathrm{~h}$ post-injection of SPIONs-FA; however, it was lowered in the next $24 \mathrm{~h}$. For the passive targeting group, SPIONs-COOH were observed to be accumulated at the tumor sites, indicating SPIONs-COOH could preferentially accumulate in the tumor tissues due to the EPR (enhanced permeability

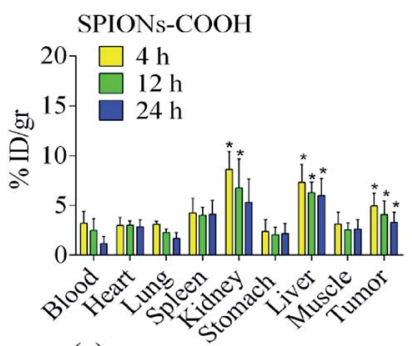

(a)

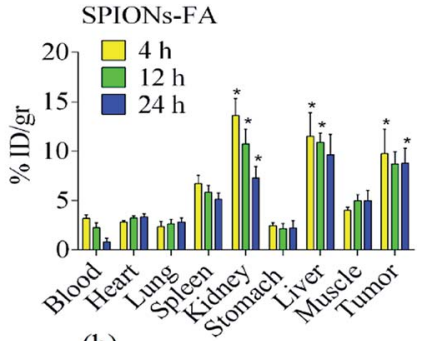

(b)
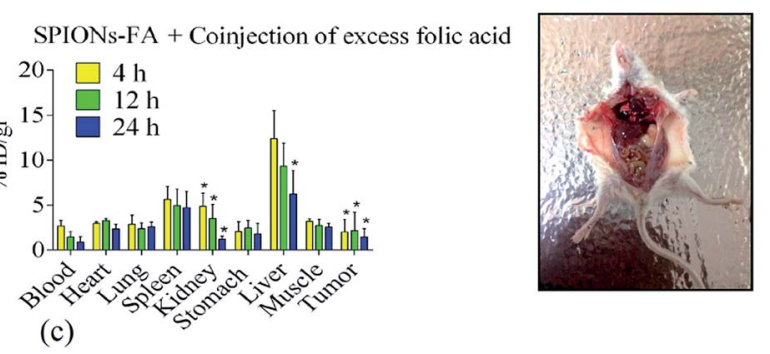

(c)

Fig. 10 Quantitative biodistribution study (AAS method). (*) indicates a significant difference compared to the control as analyzed by unpaired $t$-test followed by a Holm-Sidak post hoc test $(p<0.05)$. 
and retention) effects (Fig. 10 and S6†). In the absence of folate targeting, the EPR effect of SPIONs is the major mechanism of uptake. ${ }^{99}$ However, the amount of SPIONs-COOH at the tumor locations was less than for active SPIONs-FA $(p<0.05)$, which fully suggests that the prepared SPIONs-FA has the ability to target tumor tissues.

Experiments with co-injected FA resulted in a nearly complete blockade in the kidneys and tumor tissue showing the FAR+ specific uptake of SPIONs-FA in these tissues and organs. Generally, there is a critical aspect with the FAR targeting strategy that is related to SPIONs-FA high retention in the kidneys. In the primary urine, FARs are exposed to a high folate conjugate concentration due to the fact that the expression of the FARs happens on the luminal side of the brush border membrane. ${ }^{99,100}$ As a consequence, folate is significantly and specifically accumulated in the renal tissues. As shown in Fig. 10, a high number of SPIONs-FA are accumulated in the kidneys. The high binding and uptake of SPIONs-FA into the renal tissue is a logical consequence of FAR expression in the proximal tubule cells, which causes the high uptake and binding of SPIONs-FA in the kidneys, which is an unwanted side effect in the development of SPIONs-FA for therapeutic purposes. ${ }^{100}$ To conclude, the biodistribution results illustrated that SPIONs-FA could be an ideal targeting candidate for the FAR + metastatic cancers in biomedical applications.

\section{Conclusion}

In summary, bromelain was successfully conjugated to the folate-targeted superparamagnetic $\gamma-\mathrm{Fe}_{2} \mathrm{O}_{3}$ nanoparticles, which were coated with citric acid via a method of direct addition. A novel SPIONs-Br-FA complex was successfully synthesized, then characterized physicochemically (FT-IR, AAS, DLS, VSM, XRD, TGA, TEM, and FESEM), and tested for in vitro and in vivo tumor-targeting characteristics. A higher transport of SPIONs-FA through the mechanism of the receptor endocytosis pathway into FAR+ cells (HeLa, MDA-MB-231, and 4T1) resulted in a high accumulation of SPIONs-FA in them compared to FAR - cell lines (HSF 1184 and MDA-MB-468), which was assured to occur via qualitative and quantitative in vitro binding studies (Prussian blue assay and AAS analysis). Qualitative and quantitative biodistribution studies (AAS analysis and TEM staining method) clearly revealed the targeting of SPIONs-FA to the tumor site. The final engineered SPIONs-FA possessed desirable characteristics, adequate size, and long-term dispersibility, and could remain stable in solutions with satisfying cells and blood biocompatibility, which made it a quite exquisite and reliable choice to play a noticeable role as a drugdelivery carrier in cancer therapy. In vitro (MTT assay) and in vivo (4T1-bearing Balc/C mice model) cytotoxicity studies showed a significant dose advantage with SPIONs-Br-FA in reducing the $\mathrm{IC}_{50}$ values compared with neat $\mathrm{Br}$. Additionally, SPIONs-Br-FA was a rewarding candidate to suppress cell growth and could make an enormous morphological alternation in treated cells compared to neat Br. Furthermore, the colony formation and migration capabilities of the cells treated SPIONs-Br-FA were significantly prohibited compared to the neat Br-treated cells. In the cells treated with SPIONs-Br-FA, more signs of apoptosis and a lower number of live cells were observed compared to the cells treated with neat $\mathrm{Br}$. In other word, SPIONs-Br-FA induced a higher percentage of apoptotic cells than the neat Br. Excellent biocompatibility of the SPIONsFA and therapeutic efficacy of the SPIONs-Br-FA in FAR+ cancer cells in vitro and in vivo were demonstrated. An improved in vivo cytotoxic effect was obtained for SPIONs-Br-FA in comparison with SPIONs-Br and neat $\mathrm{Br}$, respectively. The ability of a higher targeting efficiency of SPIONs-Br-FA to the tumor site in the 4T1-bearing Balc/C mice model may have been responsible for the higher tumor inhibition efficacy than with the other SPIONs formulations in the treatment groups. Herein this study, it was conveyed that dual-functional synthesized SPIONs-Br-FA is a great candidate to inhibit the tumor growth in a live model with no damage to normal tissues. Considering the unique and favorable properties of SPIONs-Br-FA, the formulation can be fruitfully exploited to improve the deliverability of poor bioavailable drugs and may open up certain avenues in cancer therapy and thus act as an attractive and promising treatment option for patients.

\section{Conflicts of interest}

There are no conflicts to declare.

\section{References}

1 M. E. Gorre, M. Mohammed, K. Ellwood, N. Hsu, R. Paquette, P. N. Rao and C. L. Sawyers, Clinical resistance to STI-571 cancer therapy caused by BCR-ABL gene mutation or amplification, Science, 2001, 293, 876-880.

2 D. J. Slamon, B. Leyland-Jones, S. Shak, H. Fuchs, V. Paton, A. Bajamonde, T. Fleming, W. Eiermann, J. Wolter and M. Pegram, Use of chemotherapy plus a monoclonal antibody against HER2 for metastatic breast cancer that overexpresses HER2, N. Engl. J. Med., 2001, 344, 783-792.

3 X. Wang, Y. Wang, Z. G. Chen and D. M. Shin, Advances of cancer therapy by nanotechnology, Cancer Res. Treat., 2009, 41, 1-11.

4 Q. Long, Y. Xie, Y. Huang, Q. Wu, H. Zhang, S. Xiong, Y. Liu, L. Chen, Y. Wei and X. Zhao, Induction of apoptosis and inhibition of angiogenesis by PEGylated liposomal quercetin in both cisplatin-sensitive and cisplatinresistant ovarian cancers, J. Biomed. Nanotechnol., 2013, 9, 965-975.

5 K.-J. Lee, J. H. An, J.-R. Chun, K.-H. Chung, W.-Y. Park, J.-S. Shin, D.-H. Kim and Y. Y. Bahk, In vitro analysis of the anti-cancer activity of mitoxantrone loaded on magnetic nanoparticles, J. Biomed. Nanotechnol., 2013, 9, 1071-1075.

6 G. Zhang, X. Zeng and P. Li, Nanomaterials in cancertherapy drug delivery system, J. Biomed. Nanotechnol., 2013, 9, 741-750.

7 A. Jemal, F. Bray, M. M. Center, J. Ferlay, E. Ward and D. Forman, Global cancer statistics, Ca-Cancer J. Clin., 2011, 61, 69-90. 
8 R. Duncan, Polymer conjugates as anticancer nanomedicines, Nat. Rev. Cancer, 2006, 6, 688-701.

9 V. Saxena and M. D. Hussain, Polymeric mixed micelles for delivery of curcumin to multidrug resistant ovarian cancer, J. Biomed. Nanotechnol., 2013, 9, 1146-1154.

10 Y. Xu, H. Lee, Y. Hu, J. Huang, S. Kim and M. Yun, Detection and identification of breast cancer volatile organic compounds biomarkers using highly-sensitive single nanowire array on a chip, J. Biomed. Nanotechnol., 2013, 9, 1164-1172.

11 M. Ferrari, Cancer nanotechnology: opportunities and challenges, Nat. Rev. Cancer, 2005, 5, 161-171.

12 A. Gupta, S. Asthana, R. Konwar and M. K. Chourasia, An insight into potential of nanoparticles-assisted chemotherapy of cancer using gemcitabine and its fatty acid prodrug: a comparative study, J. Biomed. Nanotechnol., 2013, 9, 915-925.

13 A. Anitha, S. Uthaman, S. V Nair, R. Jayakumar and V.-K. Lakshmanan, Enhanced delivery system of flutamide loaded chitosan-dextran sulphate nanoparticles for prostate cancer, J. Biomed. Nanotechnol., 2013, 9, 335-347.

14 H. Maeda, K. Greish and J. Fang, The EPR effect and polymeric drugs: a paradigm shift for cancer chemotherapy in the 21st century, in Polym. Ther. II, Springer, 2006, pp. 103-121.

15 M. Sharma, R. Malik, A. Verma, P. Dwivedi, G. S. Banoth, N. Pandey, J. Sarkar, P. R. Mishra and A. K. Dwivedi, Folic acid conjugated guar gum nanoparticles for targeting methotrexate to colon cancer, J. Biomed. Nanotechnol., 2013, 9, 96-106.

16 L. Rao, J.-H. Xu, B. Cai, H. Liu, M. Li, Y. Jia, L. Xiao, S.-S. Guo, W. Liu and X.-Z. Zhao, Synthetic nanoparticles camouflaged with biomimetic erythrocyte membranes for reduced reticuloendothelial system uptake, Nanotechnology, 2016, 27, 85106.

17 L. Rao, L. Bu, J. Xu, B. Cai, G. Yu, X. Yu, Z. He, Q. Huang, A. Li and S. Guo, Red blood cell membrane as a biomimetic nanocoating for prolonged circulation time and reduced accelerated blood clearance, Small, 2015, 11, 6225-6236.

$18 \mathrm{~S} . \mathrm{Hu}, \mathrm{M}$. Arellano, P. Boontheung, J. Wang, H. Zhou, J. Jiang, D. Elashoff, R. Wei, J. A. Loo and D. T. Wong, Salivary proteomics for oral cancer biomarker discovery, Clin. Cancer Res., 2008, 14, 6246-6252.

19 S. K. Singh, C. Hawkins, I. D. Clarke, J. A. Squire, J. Bayani, T. Hide, R. M. Henkelman, M. D. Cusimano and P. B. Dirks, Identification of human brain tumour initiating cells, Nature, 2004, 432, 396-401.

20 M. Mahmoudi, S. Sant, B. Wang, S. Laurent and T. Sen, Superparamagnetic iron oxide nanoparticles (SPIONs): development, surface modification and applications in chemotherapy, Adv. Drug Delivery Rev., 2011, 63, 24-46, DOI: 10.1016/j.addr.2010.05.006.

21 S. Laurent, S. Dutz, U. O. Häfeli and M. Mahmoudi, Magnetic fluid hyperthermia: focus on superparamagnetic iron oxide nanoparticles, Adv. Colloid Interface Sci., 2011, 166, 8-23, DOI: 10.1016/j.cis.2011.04.003.
22 M. K. Yu, J. Park and S. Jon, Targeting strategies for multifunctional nanoparticles in cancer imaging and therapy, Theranostics, 2012, 2, 3-44, DOI: 10.7150/ thno.3463.

23 F. Bertorelle, C. Wilhelm, J. Roger, F. Gazeau, C. Ménager and V. Cabuil, Fluorescence-modified superparamagnetic nanoparticles: intracellular uptake and use in cellular imaging, Langmuir, 2006, 22, 5385-5391.

24 L. Li, W. Jiang, K. Luo, H. Song, F. Lan, Y. Wu and Z. Gu, Superparamagnetic iron oxide nanoparticles as MRI contrast agents for non-invasive stem cell labeling and tracking, Theranostics, 2013, 3, 595-615, DOI: 10.7150/ thno.5366.

25 S. Laurent, D. Forge, M. Port, A. Roch, C. Robic, L. Vander Elst and R. N. Muller, Magnetic iron oxide nanoparticles: synthesis, stabilization, vectorization, physicochemical characterizations, and biological applications, Chem. Rev., 2008, 108, 2064-2110, DOI: 10.1021/cr068445e.

26 C. Fang and M. Zhang, Multifunctional magnetic nanoparticles for medical imaging applications, J. Mater. Chem., 2009, 19, 6258-6266.

27 L. Rao, B. Cai, L.-L. Bu, Q.-Q. Liao, S.-S. Guo, X.-Z. Zhao, W.-F. Dong and W. Liu, Microfluidic ElectroporationFacilitated Synthesis of Erythrocyte Membrane-Coated Magnetic Nanoparticles for Enhanced Imaging-Guided Cancer Therapy, ACS Nano, 2017, 11(4), 3496-3505.

28 L. Rao, L. Bu, Q. Meng, B. Cai, W. Deng, A. Li, K. Li, S. Guo, W. Zhang and W. Liu, Antitumor Platelet-Mimicking Magnetic Nanoparticles, Adv. Funct. Mater., 2017, 27(9), 1604774.

29 F. Cengelli, D. Maysinger, F. Tschudi-monnet, X. Montet, C. Corot, A. Petri-fink, H. Hofmann and L. Juilleratjeanneret, Interaction of Functionalized Superparamagnetic Iron Oxide Nanoparticles with Brain Structures, J. Pharmacol. Exp. Ther., 2006, 318(1), 108-116.

30 Y. Cheng, O. Zak, P. Aisen, S. C. Harrison and T. Walz, Structure of the human transferrin receptor-transferrin complex, Cell, 2004, 116, 565-576.

31 T. Kubo, T. Sugita, S. Shimose, Y. Nitta, Y. Ikuta and T. Murakami, Targeted delivery of anticancer drugs with intravenously administered magnetic liposomes in osteosarcoma-bearing hamsters, Int. J. Oncol., 2000, 17, 309-324.

32 T. Kubo, T. Sugita, S. Shimose, Y. Nitta, Y. Ikuta and T. Murakami, Targeted systemic chemotherapy using magnetic liposomes with incorporated adriamycin for osteosarcoma in hamsters, Int. J. Oncol., 2001, 18, 121-126.

33 M.-K. Yoo, I.-K. Park, H.-T. Lim, S.-J. Lee, H.-L. Jiang, Y.-K. Kim, Y.-J. Choi, M.-H. Cho and C.-S. Cho, FolatePEG-superparamagnetic iron oxide nanoparticles for lung cancer imaging, Acta Biomater., 2012, 8, 3005-3013, DOI: 10.1016/j.actbio.2012.04.029.

34 E. Munnier, S. Cohen-Jonathan, K. Hervé, C. Linassier, M. Soucé, P. Dubois and I. Chourpa, Doxorubicin delivered to MCF-7 cancer cells by superparamagnetic iron oxide nanoparticles: effects on subcellular 
distribution and cytotoxicity, J. Nanopart. Res., 2010, 13, 959-971, DOI: 10.1007/s11051-010-0093-1.

35 M. Nasiri, S. A. H. Tabrizi, J. H. Almaki, R. Nasiri, A. Idris and S. Dabagh, Synthesis, functionalization, characterization, and in vitro evaluation of robust $\mathrm{pH}$ sensitive CFNs-PA-CaCO ${ }_{3}, R S C$ Adv., 2016, 6, 84217-84230.

36 L. Mosafa, M. Moghadam and M. Shahedi, Papain enzyme supported on magnetic nanoparticles: preparation, characterization and application in the fruit juice clarification, Chin. J. Catal., 2013, 34, 1897-1904.

37 J. R. McCarthy and R. Weissleder, Multifunctional magnetic nanoparticles for targeted imaging and therapy, Adv. Drug Delivery Rev., 2008, 60, 1241-1251.

38 K. Woo, J. Hong, S. Choi, H.-W. Lee, J.-P. Ahn, C. S. Kim and S. W. Lee, Easy synthesis and magnetic properties of iron oxide nanoparticles, Chem. Mater., 2004, 16, 2814-2818.

39 W. Wu, Q. He and C. Jiang, Magnetic iron oxide nanoparticles: synthesis and surface functionalization strategies, Nanoscale Res. Lett., 2008, 3(11), 397-415.

40 L. Li, K. Y. Mak, C. W. Leung, K. Y. Chan, W. K. Chan, W. Zhong and P. W. T. Pong, Effect of synthesis conditions on the properties of citric-acid coated iron oxide nanoparticles, Microelectron. Eng., 2013, 110, 329334.

41 T. Neuberger, B. Schöpf, H. Hofmann, M. Hofmann and B. Von Rechenberg, Superparamagnetic nanoparticles for biomedical applications: possibilities and limitations of a new drug delivery system, J. Magn. Magn. Mater., 2005, 293, 483-496.

42 C. P. Bean and J. D. Livingston, Superparamagnetism, J. Appl. Phys., 1959, 30, S120-S129.

43 R. Nasiri, J. H. Almaki, A. B. Idris, F. A. A. Majid, M. Nasiri, M. Salouti, M. Irfan, N. Amini and M. Marvibaigi, In vitro evaluation of actively targetable superparamagnetic nanoparticles to the folate receptor positive cancer cells, Mater. Sci. Eng., C, 2016, 69, 1147-1158.

44 L. Rao, Q.-F. Meng, L.-L. Bu, B. Cai, Q. Huang, Z.-J. Sun, W.-F. Zhang, A. Li, S.-S. Guo and W. Liu, Erythrocyte Membrane-Coated Upconversion Nanoparticles with Minimal Protein Adsorption for Enhanced Tumor Imaging, ACS Appl. Mater. Interfaces, 2017, 9, 2159-2168.

45 H. Lu, X. Zhao, W. Tian, Q. Wang and J. Shi, Pluronic F127folic acid encapsulated nanoparticles with aggregationinduced emission characteristics for targeted cellular imaging, RSC Adv., 2014, 4, 18460-18466.

46 M. Barz, F. Canal, K. Koynov, R. Zentel and M. J. Vicent, Synthesis and in vitro evaluation of defined HPMA folate conjugates: influence of aggregation on folate receptor (FR) mediated cellular uptake, Biomacromolecules, 2010, 11, 2274-2282.

47 L. Rao, L. Bu, B. Cai, J. Xu, A. Li, W. Zhang, Z. Sun, S. Guo, W. Liu and T. Wang, Cancer Cell Membrane-Coated Upconversion Nanoprobes for Highly Specific Tumor Imaging, Adv. Mater., 2016, 28, 3460-3466.

48 Y.-J. Surh, Cancer chemoprevention with dietary phytochemicals, Nat. Rev. Cancer, 2003, 3, 768-780.
49 N. Kalra, K. Bhui, P. Roy, S. Srivastava, J. George, S. Prasad and Y. Shukla, Regulation of p53, nuclear factor $\kappa \mathrm{B}$ and cyclooxygenase-2 expression by bromelain through targeting mitogen-activated protein kinase pathway in mouse skin, Toxicol. Appl. Pharmacol., 2008, 226, 30-37.

50 K. Eckert, E. Grabowska, R. Stange, U. Schneider, K. Eschmann and H. R. Maurer, Effects of oral bromelain administration on the impaired immunocytotoxicity of mononuclear cells from mammary tumor patients, Oncol. Rep., 1999, 6, 1191-1200.

51 S. J. Taussig and S. Batkin, Bromelain, the enzyme complex of pineapple (Ananas comosus) and its clinical application. An update, J. Ethnopharmacol., 1988, 22, 191-203.

52 H. R. Maurer, Bromelain: biochemistry, pharmacology and medical use, Cell. Mol. Life Sci., 2001, 58, 1234-1245.

53 J. C. Houck, C. M. Chang and G. Klein, Isolation of an effective debriding agent from the stems of pineapple plants, Int. J. Tissue React., 1982, 5, 125-134.

54 L. P. Hale, P. K. Greer, C. T. Trinh and C. L. James, Proteinase activity and stability of natural bromelain preparations, Int. Immunopharmacol., 2005, 5, 783-793.

55 D. M. Sarmento, D. P. Moura, S. L. Lopes and S. C. Silva, Bromelain monograph, Alternative Med. Rev., 2010, 15, 361-368.

56 K. Chobotova, A. B. Vernallis and F. A. A. Majid, Bromelain's activity and potential as an anti-cancer agent: current evidence and perspectives, Cancer Lett., 2010, 290, 148-156.

57 A. Airinei, Citric-acid - coated magnetite nanoparticles for biological applications, Eur. Phys. J. E: Soft Matter Biol. Phys., 2006, 21(2), 117-121.

58 H. Wang, D. G. Castner, B. D. Ratner and S. Jiang, Probing the orientation of surface-immobilized immunoglobulin G by time-of-flight secondary ion mass spectrometry, Langmuir, 2004, 20, 1877-1887.

59 N. Patel, M. C. Davies, M. Hartshorne, R. J. Heaton, C. J. Roberts, S. J. B. Tendler and P. M. Williams, Immobilization of protein molecules onto homogeneous and mixed carboxylate-terminated self-assembled monolayers, Langmuir, 1997, 13, 6485-6490.

60 C. Grüttner, K. Müller, J. Teller, F. Westphal, A. Foreman and R. Ivkov, Synthesis and antibody conjugation of magnetic nanoparticles with improved specific power absorption rates for alternating magnetic field cancer therapy, J. Magn. Magn. Mater., 2007, 311, 181-186.

61 M. M. Bradford, A Rapid and Sensitive Method for the Quantitation of Microgram Quantities of Protein Utilizing the Principle of Protein-Dye Binding, Anal. Bioanal. Chem., 1976, 254, 248-254.

62 N. H. A. Ngadiman, A. Idris, M. Irfan, D. Kurniawan, N. M. Yusof and R. Nasiri, $\gamma-\mathrm{Fe}_{2} \mathrm{O}_{3}$ nanoparticles filled polyvinyl alcohol as potential biomaterial for tissue engineering scaffold, J. Mech. Behav. Biomed. Mater., 2015, 49, 90-104, DOI: 10.1016/j.jmbbm.2015.04.029.

63 T. Mosmann, Rapid Colorimetric Assay for Cellular Growth and Survival: Application to Proliferation and Cytotoxicity Assays, J. Immunol. Methods, 1983, 65, 55-63. 
64 N. Amini, F. A. Abdul Majid, M. Marvibaigi, E. Supriyanto, S. K. Jaganathan, W. Tet Soon, R. Nasiri and J. Hamzehalipour, Cervicare ${ }^{\mathrm{TM}}$ induces apoptosis in HeLa and CaSki cells through ROS production and loss of mitochondrial membrane potential, $R S C A d v$., 2016, 6, 24391-24417, DOI: 10.1039/C5RA25654B.

65 M. B. A. Gani, R. Nasiri, J. H. Almaki, F. A. A. Majid, M. Marvibaigi, N. Amini, S. H. Chermahini and M. Mashudin, In Vitro Antiproliferative Activity of Fresh Pineapple Juices on Ovarian and Colon Cancer Cell Lines, Int. J. Pept. Res. Ther., 2015, 21, 353-364, DOI: 10.1007/ s10989-015-9462-z.

66 J. F. Kukowska-Latallo, K. A. Candido, Z. Cao, S. S. Nigavekar, I. J. Majoros, T. P. Thomas, L. P. Balogh, M. K. Khan and J. R. Baker, Nanoparticle targeting of anticancer drug improves therapeutic response in animal model of human epithelial cancer, Cancer Res., 2005, 65, 5317-5324.

67 L. Landini and R. Sarnelli, Evaluation of the attenuation coefficients in normal and pathological breast tissue, Med. Biol. Eng. Comput., 1986, 24, 243-247.

68 J. Lipka, M. Semmler-Behnke, R. A. Sperling, A. Wenk, S. Takenaka, C. Schleh, T. Kissel, W. J. Parak and W. G. Kreyling, Biodistribution of PEG-modified gold nanoparticles following intratracheal instillation and intravenous injection, Biomaterials, 2010, 31, 6574-6581.

69 X. Huang, I. H. El-Sayed, W. Qian and M. A. El-Sayed, Cancer cell imaging and photothermal therapy in the near-infrared region by using gold nanorods, J. Am. Chem. Soc., 2006, 128, 2115-2120.

70 F.-K. Huang, W.-C. Chen, S.-F. Lai, C.-J. Liu, C.-L. Wang, C.-H. Wang, H.-H. Chen, T.-E. Hua, Y.-Y. Cheng and M. K. Wu, Enhancement of irradiation effects on cancer cells by cross-linked dextran-coated iron oxide (CLIO) nanoparticles, Phys. Med. Biol., 2009, 55, 469.

71 C. Sun, R. Sze and M. Zhang, Folic acid-PEG conjugated superparamagnetic nanoparticles for targeted cellular uptake and detection by MRI, J. Biomed. Mater. Res., Part A, 2006, 78, 550-557.

72 T. Chen, T. Cheng, Y. Hung, K. Lin, G. Liu and Y. Wang, Targeted folic acid-PEG nanoparticles for noninvasive imaging of folate receptor by MRI, J. Biomed. Mater. Res., Part A, 2008, 87, 165-175.

73 M.-K. Yoo, I.-K. Park, H.-T. Lim, S.-J. Lee, H.-L. Jiang, Y.-K. Kim, Y.-J. Choi, M.-H. Cho and C.-S. Cho, FolatePEG-superparamagnetic iron oxide nanoparticles for lung cancer imaging, Acta Biomater., 2012, 8, 3005-3013.

74 J. Sudimack and R. J. Lee, Targeted drug delivery via the folate receptor, Adv. Drug Delivery Rev., 2000, 41, 147-162.

75 M. Prabaharan, J. J. Grailer, S. Pilla, D. A. Steeber and S. Gong, Folate-conjugated amphiphilic hyperbranched block copolymers based on Boltorn ${ }^{\circledR} \mathrm{H} 40$, poly(l-lactide) and poly(ethylene glycol) for tumor-targeted drug delivery, Biomaterials, 2009, 30, 3009-3019.

76 M. Prabaharan, J. J. Grailer, D. A. Steeber and S. Gong, Thermosensitive Micelles Based on Folate-Conjugated Poly( $N$-vinylcaprolactam)-block-Poly (ethylene glycol) for
Tumor-Targeted Drug Delivery, Macromol. Biosci., 2009, 9, 744-753.

77 M. Prabaharan, J. J. Grailer, S. Pilla, D. A. Steeber and S. Gong, Gold nanoparticles with a monolayer of doxorubicin-conjugated amphiphilic block copolymer for tumor-targeted drug delivery, Biomaterials, 2009, 30, 6065-6075.

78 M. Prabaharan, J. J. Grailer, S. Pilla, D. A. Steeber and S. Gong, Amphiphilic multi-arm-block copolymer conjugated with doxorubicin via $\mathrm{pH}$-sensitive hydrazone bond for tumor-targeted drug delivery, Biomaterials, 2009, 30, 5757-5766.

79 X. Yang, J. J. Grailer, S. Pilla, D. A. Steeber and S. Gong, Tumor-targeting, pH-responsive, and stable unimolecular micelles as drug nanocarriers for targeted cancer therapy, Bioconjugate Chem., 2010, 21, 496-504.

$80 \mathrm{~S}$. A. Wahajuddin, Superparamagnetic iron oxide nanoparticles: magnetic nanoplatforms as drug carriers, Int. J. Nanomed., 2012, 7, 3445.

81 T. K. Jain, M. A. Morales, S. K. Sahoo, D. L. Leslie-Pelecky and V. Labhasetwar, Iron oxide nanoparticles for sustained delivery of anticancer agents, Mol. Pharm., 2005, 2, 194-205.

82 M. Szekeres, I. Y. Tóth, E. Illés, A. Hajdú and I. Zupkó, Chemical and Colloidal Stability of Carboxylated CoreShell Magnetite Nanoparticles Designed for Biomedical Applications, Int. J. Mol. Sci., 2013, 67, 14550-14574, DOI: 10.3390/ijms140714550.

83 A. S. G. Ali, M. A. Reza, H. Eshghi, A. Sazgarnia and A. R. Montazerabadi, Cancerous Cells Targeting and Destruction Using Folate Conjugated Gold Nanoparticles, in Dynamic Biochemistry, Process Biotechnology and Molecular Biology, Global Science Books, 2010, vol. 4(Special Issue 1), pp. 6-12, http://www.globalsciencebooks.info/Online/ GSBOnline/images/2010/DBPBMB_4(SI1)/DBPBMB_4(SI1) 6-12o.pdf.

84 L. Vigderman and E. R. Zubarev, Therapeutic platforms based on gold nanoparticles and their covalent conjugates with drug molecules, Adv. Drug Delivery Rev., 2013, 65, 663-676, DOI: 10.1016/j.addr.2012.05.004.

85 F. Danhier, E. Ansorena, J. M. Silva, R. Coco, A. Le Breton and V. Préat, PLGA-based nanoparticles: an overview of biomedical applications, J. Controlled Release, 2012, 161, 505-522, DOI: 10.1016/j.jconrel.2012.01.043.

86 S. D. Brown, P. Nativo, J.-A. Smith, D. Stirling, P. R. Edwards, B. Venugopal, D. J. Flint, J. A. Plumb, D. Graham and N. J. Wheate, Gold nanoparticles for the improved anticancer drug delivery of the active component of oxaliplatin, J. Am. Chem. Soc., 2010, 132, 4678-4684.

87 T. Wang, H. Wu, W. Wang, F. Lin, P. Lou, M. Shieh and T. Young, The development of magnetic degradable DPBioglass for hyperthermia cancer therapy, J. Biomed. Mater. Res., Part A, 2007, 83, 828-837.

88 G. A. Mansoori, K. S. Brandenburg and A. Shakeri-zadeh, A Comparative Study of Two Folate-Conjugated Gold 
Nanoparticles for Cancer Nanotechnology Applications, Cancers, 2010, 7, 1911-1928, DOI: 10.3390/cancers2041911.

89 B. W. Stewart, Mechanisms of apoptosis: integration of genetic, biochemical, and cellular indicators, J. Natl. Cancer Inst., 1994, 86, 1286-1296.

90 S. Van Cruchten and W. Van Den Broeck, Morphological and biochemical aspects of apoptosis, oncosis and necrosis, Anat., Histol., Embryol., 2002, 31, 214-223.

91 S. Desagher and J.-C. Martinou, Mitochondria as the central control point of apoptosis, Trends Cell Biol., 2000, 10, 369377.

92 J. A. Hickman, Apoptosis induced by anticancer drugs, Cancer Metastasis Rev., 1992, 11, 121-139.

93 S. H. Kaufmann and W. C. Earnshaw, Induction of apoptosis by cancer chemotherapy, Exp. Cell Res., 2000, 256, 42-49.

94 D. E. Fisher, Apoptosis in cancer therapy: crossing the threshold, Cell, 1994, 78, 539-542.

95 D. Hanahan and R. A. Weinberg, The hallmarks of cancer, Cell, 2000, 100, 57-70.
96 P. S. Steeg, Tumor metastasis: mechanistic insights and clinical challenges, Nat. Med., 2006, 12, 895-904.

97 F. van Zijl, G. Krupitza and W. Mikulits, Initial steps of metastasis: cell invasion and endothelial transmigration, Mutat. Res., Rev. Mutat. Res., 2011, 728, 23-34.

98 P. Bhatnagar, S. Patnaik, A. K. Srivastava, M. K. R. Mudiam, Y. Shukla, A. K. Panda, A. B. Pant, P. Kumar and K. C. Gupta, Anti-cancer activity of bromelain nanoparticles by oral administration, J. Biomed. Nanotechnol., 2014, 10, 3558-3575.

99 J. Razjouyan, H. Zolata, O. Khayat, F. Nowshiravan, N. Shadanpour and M. Mohammadnia, Synthesis and evaluation of radiolabeled, folic acid-PEG conjugated, amino silane coated magnetic nanoparticles in tumor bearing Balb/C mice, Nukleonika, 2015, 60, 479-502, DOI: 10.1515/nuka-2015-0066.

100 C. Müller, F. Forrer, R. Schibli, E. P. Krenning and M. de Jong, SPECT study of folate receptor-positive malignant and normal tissues in mice using a novel 99mTcradiofolate, J. Nucl. Med., 2008, 49, 310-317, DOI: 10.2967/jnumed.107.045856. 